\title{
The Japanese Society of Hypertension Guidelines for Self-monitoring of Blood Pressure at Home (Second Edition)
}

\author{
Yutaka Imai ${ }^{1}$, Kazuomi Kario ${ }^{2}$, Kazuyuki Shimada ${ }^{3}$, Yuhei Kawano ${ }^{4}$, Naoyuki Hasebe ${ }^{5}$, Hideo Matsuura ${ }^{6}$, \\ Takuya Tsuchihashi ${ }^{7}$, Takayoshi Ohkubo ${ }^{8}$, Iwao Kuwajima ${ }^{9}$ and Masaaki Miyakawa ${ }^{10}$, as members of the \\ Japanese Society of Hypertension Committee for Guidelines for Self-monitoring of Blood Pressure at Home
}

Hypertension Research (2012) 35, 777-795; doi:10.1038/hr.2012.56

\section{INTRODUCTION}

Since Riva-Rocci invented indirect brachial cuff sphygmomanometry in $1896^{1}$ and Korotkoff proposed the auscultatory method in $1905{ }^{2}$ the method for blood pressure (BP) measurements has remained essentially unchanged for the past 100 years.

In 1969, Posey et al. ${ }^{3}$ identified mean BP on the basis of the cuff-oscillometric method. With subsequent theoretical and technical improvements, the method to determine systolic and diastolic BP ( $\mathrm{S}$ and $\mathrm{D}$, respectively) was introduced to the cuff-oscillometric method. As a result, many of the automatic electronic sphygmomanometers available today have adopted this method, and those different from the auscultatory method have begun to be used in general clinical practice. Since the advent of indirect methods for sphygmomanometry, the past century has developed the practical and clinical sciences of hypertension. However, BP information necessary for the diagnosis and treatment of hypertension is still obtained essentially on the basis of casual measurements at the outpatient clinic (clinic BP). However, the reliability of clinic BP was called into question 40 years after the advent of indirect sphygmomanometry. In 1940, Ayman and Goldshine $^{4}$ widely adopted the concept of self-BP measurements in the field of clinic BP measurements and demonstrated discrepancies between clinic BP and self-BP measurements. Bevan, ${ }^{5}$ in the United Kingdom, first reported the results of ambulatory $\mathrm{BP}(\mathrm{ABP})$ monitoring (ABPM) using a direct arterial BP measurement method in 1969, and showed that human BP changes markedly with time. The quantity and quality of BP information vary greatly according to different methods, and the problem of interpreting clinic BP, which is obtained specifically in a medical environment, has been an issue in the clinical practice of hypertension during the past 50 years.

However, the practice and epidemiology of hypertension still depend entirely on BP information obtained in a medical environment (clinic $\mathrm{BP} / \mathrm{BP}$ at a health examination), resulting in the accumulation of a great quantity of data about BP in a medical environment. For this reason, clinic BP remains the gold standard for the diagnosis and treatment of hypertension. However, data regarding $\mathrm{ABP}$ or self-BP measurements at home (home BP) have also been accumulating for the past 30 years, and BP information, other than clinic BP, has been shown to have greater clinical significance than clinic BP. Many of these findings are the result of clinical and epidemiological studies.

Essentially, as $\mathrm{ABP}$ and home $\mathrm{BP}$ are accompanied by qualitative improvements and quantitative increases in information compared with clinic BP, they are considered to have greater clinical significance. For example, in ABPM by an indirect method widely used today, $\mathrm{BP}$ values can be obtained every 15 or $30 \mathrm{~min}$ on a particular day. Therefore, 50-100 BP values can be measured in the time course of one day. On the other hand, with home BP measurements, BP values are obtained at least at 2 time points in a day, that is, morning and evening, providing time-related BP information at 60 time points in a month. In addition to such definite increases in the quantity of information, BP information as a function of time leads to qualitative improvements. The application of the cuff-oscillometric method to sphygmomanometric devices associated with recent improvements in electronic technology and the clinical utilization of ABPM and home BP measurements are a paradigm shift in the history of the diagnosis and treatment of hypertension by indirect BP measurements.

As mentioned above, ABPM usually allows for the evaluation of BP levels on a particular day in relation to the time of day. For ABPM, special devices are necessary. Although the price of the ABPM system was reduced recently, it still costs hundreds of thousands of yen. Hypertension is a chronic disease; therefore BP must be evaluated with repeated measurements over a long period of time. However, it is impractical to perform $\mathrm{ABPM}$ in many hypertensive patients,

${ }^{1}$ Department of Planning for Drug Development and Clinical Evaluation, Tohoku University Graduate School of Pharmacological Sciences, Sendai, Japan; ${ }^{2}$ Department of Medicine, Division of Cardiovascular Medicine, Jichi Medical University School of Medicine Shimotsuke, Tochigi, Japan; ${ }^{3}$ Jichi Medical University Hospital, Yakushiji, Japan; ${ }^{4}$ Division of Hypertension and Nephrology, National Cerebral and Cardiovascular Center, Suita, Japan; ${ }^{5}$ Department of Internal Medicine, Division of Cardiology, Nephrology, Pulmonology and Neurology, Asahikawa Medical University, Asahikawa, Japan; ${ }^{6}$ Saiseikai Kure Hospital, Kure, Japan; ${ }^{7}$ Division of Hypertension, National Kyushu Medical Center, Fukuoka, Japan; ${ }^{8}$ Department of Health Science, Shiga University of Medical Science, Otsu, Japan; ${ }^{9}$ Department of Cardiology, Tokyo Metropolitan Geriatric Hospital Tokyo, Japan and ${ }^{10}$ Miyakawa Clinic, Yokohama, Japan 
estimated to be 40 million in Japan, owing to the increase in physical, mental and economical burden to the patients. Therefore, ABPM is often used today to diagnose secondary hypertension, refractory hypertension and pathological hypotension, and to evaluate the nighttime BP and short-time variabilities in BP.

More than 15 million devices for home BP measurements are manufactured annually in Japan, and 35 million units have been distributed to Japanese households. ${ }^{6}$ Units are purchased with people's or patients' own money, and are rapidly spreading in Japan. As a result, the quantity of information about BP for the diagnosis and treatment of hypertension has markedly increased. Furthermore, as home BP measurements during sleep, in the morning and in the evening have become available, ${ }^{7}$ further improvements in the quality of information are anticipated.

However, even today, the quality of home BP measurements is considered unreliable by a certain proportion of clinicians. The greatest reason for this is the lack of standardization to ensure the quality of medical information, such as standardization of the equipment, measurement conditions, and the frequency and period of measurements. In addition, the diagnostic threshold for home BP values obtained by a standardized method has not been fully established. This problem affects the establishment of home BP measurements for medical decision making.

In connection with these points, the 6th and 7th Reports of the Joint National Committee on Prevention, Detection, Evaluation, and Treatment of high BP (JNC-VI and JNC7), 8,9 the 1999 World Health Organization-International Society of Hypertension Guidelines for the Management of Hypertension, ${ }^{10}$ the Guidelines for the Treatment of Hypertension 2004 by the Japanese Society of Hypertension ${ }^{11}$ and the 2003 European Society of Hypertension-European Society of Cardiology Guidelines for the Management of Arterial Hypertension (ESH-ESC), ${ }^{12}$ all have emphasized the importance of home BP measurements as BP information, based on clinical and epidemiological evidence that home BP measurements more accurately reflected target organ damage and predicted outcomes than clinic BP.

On the basis of these guidelines and original evidence obtained in Japan, the Japanese Society of Hypertension published the Japanese Society of Hypertension Guidelines for Self-monitoring of Blood Pressure at Home in 2003, the first guidelines for home BP measurements in the world. ${ }^{13}$ Thereafter, these guidelines were presented as recommendations by the American Heart Association (AHA) in $2003,{ }^{14}$ practice guidelines for the measurement of BP by the ESH in $2005,{ }^{15}$ Canadian Hypertension Educational Program recommendations, ${ }^{16} \mathrm{ESH}$ guidelines for BP monitoring at home in 2008, ${ }^{17} \mathrm{ESH} /$ ESC hypertension guidelines in $2007,{ }^{18}$ and as a joint statement by the American Heart Association/American Society of Hypertension/ Preventive Cardiovascular Nurses Association (AHA/ASH/PCNA) in 2008. ${ }^{19}$ The Japanese Society of Hypertension established guidelines for the management of hypertension in 2009 (JSH 2009), adopting the policies of Western guidelines. ${ }^{20}$ The JSH 2009 Guidelines emphasized strict $24-\mathrm{hBP}$ control and noted the importance of home BP measurements.

Thus, many guidelines for home BP measurements have been issued, not only in Japan but also internationally. However, according to a report from Japan in 2010, most Japanese clinicians recognized the clinical value of home BP, but had insufficient understanding about the conditions in which home BP measurements were taken. It was also shown that only $20 \%$ of clinicians recognized the reference value of home BP measurements. ${ }^{21}$ On the basis of the JSH 2009 Guidelines and the Working Group of Guidelines for Self-monitoring of Blood Pressure at Home provided by the Scientific Committee, the
Japanese Society of Hypertension decided to compile minimum requirements and establish guidelines for home BP measurements, to revise a new edition of the 2003 guidelines, to integrate the latest information and to comment on its details for both clinicians and hypertension specialists.

This Working Group intends to standardize the conditions of home BP measurements in Japan, authorize home BP values obtained by a standardized method for the diagnosis and treatment of hypertension, and resolve clinical confusion. It also aims to establish a firmer standpoint of home BP measurements in the diagnosis and treatment of hypertension.

The present guidelines are designed to be used by both general practitioners and hypertension specialists for home BP measurements essentially in adults.

\section{CHAPTER 1. CLINICAL SIGNIFICANCE AND APPLICATION OF HOME BP}

\section{SUMMARY}

- Home BP is highly reproducible.

- Home BP has a greater prognostic value than clinic BP.

- Home BP is extremely effective for the evaluation of drug effects and their duration.

- Home BP can also be used for telemedicine.

- The introduction of home BP to the diagnosis and treatment of hypertension facilitates long-term BP control.

- Home BP measurements improve the adherence to medications and medical consultations.

- Home BP can detect seasonal variations and long-term changes in BP.

- Home BP is essential for the diagnosis of white-coat hypertension and masked hypertension.

- Home BP measurements detect morning hypertension, and nighttime BP during sleep can also be obtained with certain devices.

- Home BP is particularly important for the diagnosis and treatment of hypertension in diabetes mellitus, pregnancy, children and renal diseases.

- Home BP has a great effect on the medical economy.

Today, BP is measured under non-clinical settings by either ABPM or home BP measurements. These two methods have different characteristics as well as many similarities. One of the similarities is that the procedures provide more information than clinic BP measurements. ABPM provides BP information at many points on a particular day during unrestricted routine daily activities, and the information obtained by ABPM may be compared with serial typhoon information regarding its characteristics in relation to time. On the other hand, home BP measurements provide a lot of BP information obtained under fixed conditions and at nearly fixed hours of the day over a long period of time, which may be compared with fixed-point observations. Whether they are compared with serial typhoon information or fixedpoint observations, both methods provide time-related BP information.

As home BP is measured under fixed conditions and at nearly the same time points during the day over a long period of time, its mean value is stable, and short- and long-term reproducibilities are high. ${ }^{22-24}$ On the other hand, as ABP is affected by various internal and external environmental factors on a particular day, the reproducibility of its mean value is inferior to that of home $\mathrm{BP},{ }^{23-25}$ and the reproducibility of circadian BP variations based on ABPM is not enough. ${ }^{26-29}$ Table 1 
Table 1 Characteristics of each type of blood pressure measurement

\begin{tabular}{|c|c|c|c|}
\hline & Clinic blood pressure & Ambulatory blood pressure & Home blood pressure \\
\hline Frequency of measurement & Low & High & High \\
\hline Measurement standardization & Possible (difficult) & Unnecessary & Possible \\
\hline Evaluation of short-term variability & Impossible & Possible & Impossible \\
\hline Evaluation of diurnal changes (evaluation of nocturnal blood pressure) & Impossible & Possible & Partly possible ${ }^{a}$ \\
\hline Drug efficacy assessment & Possible & Appropriate & Appropriate \\
\hline Evaluation of the duration of drug efficacy & Impossible & Possible & Possible \\
\hline Evaluation of long-term changes & Partly possible & Impossible & Possible \\
\hline Reproducibility & Unfavorable & Favorable & Most favorable \\
\hline White-coat phenomenon & Present & Absent & Absent \\
\hline
\end{tabular}

From Imai et al..$^{30}$ and JSH 2009 guidelines (modified partly).

aHome blood-pressure-measuring devices that can monitor blood pressure during sleep at night are available.

summarizes the characteristics of home BP compared with clinic BP and $\mathrm{ABP}^{30}$

\section{1) HOME BP AND PROGNOSIS}

The prognostic significance of home $\mathrm{BP}$ has been reported to be comparable to, ${ }^{31,32}$ or slightly better than, that of ABP. The high prognostic significance of home $\mathrm{BP}$ is considered to be derived from the stability of BP information. ${ }^{33-41}$ Evidence has also shown that home $\mathrm{BP}$ reflects target organ damage with similar or higher reliability than $\mathrm{ABP}^{42-46}$

ABPM provides data on short-term BP variability every $15-30 \mathrm{~min}$, and these values are reported to have prognostic significance. ${ }^{46-50}$ The day-to-day variability of BP detected by home BP measurements has also been reported to predict the risk of cerebrovascular and cardiovascular diseases. ${ }^{51,52}$

Heart rate measured simultaneously with home BP also has a prognostic significance. ${ }^{53}$

\section{2) HOME BP AND CLINICAL PHARMACOLOGY OF ANTIHYPERTENSIVE DRUGS}

As home BP provides a stable mean value and ensures high reproducibility, it is extremely effective for the evaluation of drug effects and their duration. Home BP eliminates the placebo effect ${ }^{54}$ and records the responses to antihypertensive drugs more accurately than $\mathrm{ABP},{ }^{55}$ and, as such, is considered optimal for evaluating the effects of antihypertensive drugs. ${ }^{56,57}$ Consequently, home BP reduces the number of subjects necessary for the evaluation of drug effects compared with $\mathrm{ABP}$, and markedly reduces the number necessary when compared with clinic BP. ${ }^{24,55,56}$

Evaluation of the duration of drug effects has been considered possible by the use of the trough/peak (T/P) ratio based on $A B P$. However, as the reproducibility of $\mathrm{ABP}$ is not always adequate, the reproducibility of the $\mathrm{T} / \mathrm{P}$ ratio is also unsatisfactory. ${ }^{58,59}$ It has recently been reported that the morning/evening (M/E) or evening/ morning $(\mathrm{E} / \mathrm{M})$ ratio obtained from home $\mathrm{BP}$ measurements is very effective in evaluating the duration of drug effects. ${ }^{57,58,60}$

\section{3) HOME BP AND TELEMEDICINE}

With the advance of devices for home BP measurements, BP values have begun to be stored as electronic data. As a result, such data have been transmitted via telephone lines or the internet, and are widely used for decision making ${ }^{61-65}$ and clinical pharmacological evaluations. ${ }^{65,66}$ Improvements in BP control by means of such telemedicine have been reported. ${ }^{61,64,67-71}$

\section{4) HOME BP AND BP CONTROL}

The Japanese and International guidelines recognize home BP measurements as an optimal tool for long-term BP control. ${ }^{17-20}$

The introduction of home BP measurements in the diagnosis and treatment of hypertension facilitates the attainment of a goal BP compared with BP management based on clinic BP alone. ${ }^{6,70,72-76}$ By implementing antihypertensive therapy according to home $\mathrm{BP}$, the goal BP can be achieved sooner. ${ }^{67,77}$

BP control has been reported to be improved by combining home BP measurements with behavioral therapy ${ }^{78}$ Home BP measurements also reduce the frequency of clinic consultations ${ }^{67}$ and elevate the participation rate to medical treatment. ${ }^{79}$

As home BP is measured and interpreted by the patients themselves, the possibility of self-regulation of antihypertensive medication according to home BP has become relevant in hypertension management. ${ }^{71,80,81}$

\section{5) HOME BP AND ADHERENCE}

Home BP measurements require an active commitment by the patients themselves in medical care and health management, and results in a marked improvement in the adherence to medication. ${ }^{82,83}$ High adherence to home BP measurements has also been reported to improve BP control. ${ }^{84}$ Patients with high adherence to home BP measurements have also shown high adherence to exercise or dietary intervention. ${ }^{85}$

\section{6) HOME BP AND SEASONAL CHANGES IN BP}

Unlike ABP, home BP is effective in evaluating long-term changes in BP. For example, home BP can detect seasonal variations in BP. ${ }^{86-91}$ The monitoring of seasonal changes in home BP facilitates the titration of antihypertensive drugs.

\section{7) HOME BP, AND PHYSIOLOGICAL AND PATHOPHYSIOLOGICAL CONDITIONS}

Home BP can detect slight changes in BP mediated by modifications in lifestyle or by exposure to stress, as well as small changes in BP in response to antihypertensive drugs. For example, home BP can detect the depressor effect caused by the intake of fruits and vegetables in a population ${ }^{92}$ or by physical training, ${ }^{93}$ the hypertensive response to passive smoking in a population, ${ }^{94}$ the relationship with the longevity of parents and low BP in children, ${ }^{95}$ the relationship of combinations of hypertension candidate genes with the incidence of hypertension, ${ }^{96}$ and so on. In a crossover study of calcium supplementation assessed by office, home and ambulatory BPs, the small reduction in BP was 
significant only for home $\mathrm{BP} .{ }^{97}$ Serial measurements of home BP also detected time-related biphasic changes in morning and evening BPs with alcohol consumption and restriction in hypertensive patients. ${ }^{98}$ Therefore, home BP measurements provide an excellent index for the evaluation of $\mathrm{BP}$ changes in individuals and for the comparison of $\mathrm{BP}$ among individuals and groups.

In particular, the reliability and precision of $\mathrm{BP}$ as a phenotype are determinants of the results of gene-related studies, and home BP is considered to be extremely useful in such studies. ${ }^{99}$

\section{8) MEASUREMENT OF HOME BP UNDER SPECIAL CONDITIONS}

Home BP is information obtained under a non-medical setting and essentially by self-measurement. With home BP measurements, timerelated $\mathrm{BP}$ information can be obtained over a long period. On the basis of these characteristics, home BP provides the information indispensable for the diagnosis of white-coat hypertension, masked hypertension or early-morning hypertension. Also, some home BPmeasuring devices provide BP information during sleep at night. Moreover, home BP measurements are used as a means to average BP over a long period of time and, thus, are used as a means to transform essentially highly variable $\mathrm{BP}$ values into stable $\mathrm{BP}$ information in the form of averaged BP. This is applied to BP measurements for pregnant women and children. Many studies have also reported the usefulness of home BP measurements for the diagnosis and treatment of hypertension in dialysis patients and diabetic patients, in whom daily management of BP mediates critical results on their outcome.

\section{White-coat hypertension/white-coat phenomenon (effect)}

White-coat hypertension is a condition in which BP measured in a medical setting (outpatient clinic, and so on) is always in the hypertensive range $(\geqslant 140 / 90 \mathrm{~mm} \mathrm{Hg})$ and that measured in a nonmedical setting (home BP, ABP) is always normal. Generally, this condition is diagnosed by home BP measurements. Although the AHA recommends the screening of patients for white-coat hypertension by home BP measurements with the final diagnosis by $\mathrm{ABPM},{ }^{14}$ it is practical to diagnose this condition using home BP in general clinical practice, while ABPM should be considered when necessary. The term 'white-coat hypertension' is used for untreated patients. Differences between clinic and home BPs are also observed in patients being treated. This condition is called the white-coat phenomenon (effect). If a patient being treated exhibits hypertension on BP measurements in a medical setting but normal BP measurements in a non-medical setting, the condition must be specified as 'white-coat hypertension under treatment'. Home BP measurements are indispensable for the diagnosis of white-coat hypertension or the white-coat phenomenon. Although the potential harmfulness of white-coat hypertension remains controversial, studies based on home BP have reported that white-coat hypertension tends to advance to true hypertension more often than true normotension. ${ }^{100,101}$

The frequency of white-coat hypertension based on home BP measurements has been reported to be $38-58 \%$ in cohorts of the general population, ${ }^{102-104} 15 \%$ in untreated patients with hypertension $^{105}$ and $12-19 \%$ in hypertensive patients being treated. ${ }^{106-108}$

The prognosis of white-coat hypertension depends on home BP levels. If high normal BP home measurements (125-135/ $80-85 \mathrm{~mm} \mathrm{Hg}$; see Chapter 9) are regarded as normal, the prognosis of white-coat hypertension tends to be poor. However, if optimal BP levels (<120/80 mm Hg; see Chapter 9) are regarded as normal home $\mathrm{BP}$, the prognosis of white-coat hypertension is generally judged to be favorable.

\section{Masked hypertension}

In contrast to white-coat hypertension, when clinic BP is normal, but the values measured in a non-medical setting are in the hypertensive range, this condition is called masked hypertension. This condition is generally detected by home BP measurements, and is observed in both treated and untreated patients. The condition is called masked hypertension because hypertension is masked on measurements taken in the clinic. Masked hypertension detected by home BP measurements in the morning may be related to elevations in BP during this time as part of diurnal BP fluctuations such as those in non-dippers, risers and the morning surge, ${ }^{109,110}$ or as a result of an insufficient duration of the effect of antihypertensive medication, causing an increase in BP to hypertensive levels before the next dosing. ${ }^{111}$ The prognosis of masked hypertension is poor. ${ }^{41,112}$ Workplace hypertension is also a form of masked hypertension. The frequency of masked hypertension based on home BP is reported to be about $10 \%$ in cohorts of the general population ${ }^{103,104}$ and $11-33 \%$ in hypertensive patients under treatment. ${ }^{108,113,114}$

\section{Morning hypertension, and morning and evening home BP}

Although there is no precise definition of morning hypertension, a condition with a specifically high BP after waking early in the morning may be referred to as morning hypertension. According to the absolute values of home BP or ABP, a value of $\geqslant 135 / 85 \mathrm{~mm} \mathrm{Hg}$ in the morning, for example, may be regarded as morning hypertension; however, the value in the morning must be higher than that in the evening to confirm that $\mathrm{BP}$ is high specifically in the morning. Morning hypertension may be the result of one of two patterns of diurnal BP changes. One is the morning surge, which is a rapid elevation in BP around awakening from a low nocturnal level. The other is high $\mathrm{BP}$ in the morning observed in non-dippers, who show no normal nocturnal decrease in BP, or risers, who show nighttime elevations in BP. Both patterns are considered to be possible risk factors of cardiovascular diseases. ${ }^{109,110,115-118}$

Home BP is usually measured two times a day, that is, in the morning and evening. According to reports from Japan, home BP is higher in the morning than in the evening. ${ }^{114,119}$ The major causes of this difference in BP between the morning and evening are reported to be antihypertensive treatment, alcohol intake and taking a bath. ${ }^{120-122}$ Those who exhibit large morning-evening differences in BP have marked target organ damage, such as left ventricular hypertrophy. ${ }^{123-126}$ However, home BP measured in the evening also has a high prognostic significance. $^{117,127}$

In contrast, there have been a number of reports from Western countries that home BP does not differ between the morning and evening, or that home BP is higher in the evening than in the morning. ${ }^{128,129}$ This may be partly explained by the difference in evening BP measurement times (mostly early in the evening in Western countries, and before going to bed in Japan). Differences in lifestyle between Europeans and Japanese (the latter has the habit of taking a bath in the evening) may also be related.

\section{Nighttime BP}

During sleep at night, BP is usually measured by ABPM. Recently, home BP-measuring devices capable of monitoring BP during sleep at night have been developed, and their performance has been close or equal to that of ABPM.,130,131 Home BP-measuring devices with similar functions to ABPM have also been developed, and the differences between these two methods have been narrowed. ${ }^{132,133}$ 
Generally, the state of sleep is evaluated the next morning according to whether the subject woke up due to operation of the device. However, as $\mathrm{BP}$ is measured every $30 \mathrm{~min}$ to $1 \mathrm{~h}$ by ABPM during the night, that is, 8-16 times during sleep, the relationship between the state of sleep and BP cannot be evaluated using this method. Using a home BPmonitoring device, $\mathrm{BP}$ during sleep is measured once or twice during the night, although the frequency of measurement can be preset freely, and is therefore able to capture the BP in relation to the quality of sleep at the time of the measurement. This is a great advantage of this method. ${ }^{7}$

Recently, midnight BP and diurnal changes in BP, as well as morning BP, have become of interest because of their relationships with target organ damage and prognosis. Decreases of $10-20 \%$ in nocturnal BP compared with daytime BP are classified as a normal pattern of diurnal changes (dipper), decreases of $0-10 \%$ as a nonocturnal-dip type (non-dipper), elevations in BP during the nighttime compared with the daytime as a nocturnal elevation type (riser), and decreases of $\geqslant 20 \%$ in nocturnal BP as an excessive decrease type (extreme dipper). The prognosis has been poor in non-dippers and risers. ${ }^{109,134-137}$ In non-dippers and risers, hypertensive target organ damage, such as asymptomatic lacunar infarction, left ventricular hypertrophy and microalbuminuria, are observed more frequently than in dippers. ${ }^{135,136,138}$ Prospective studies have shown that the risk of cardiovascular diseases is higher in non-dippers than in dippers. ${ }^{109,136-138}$ According to the results of the Ohasama study, the risk of cardiovascular diseases is high in non-dippers even if they are normotensive. ${ }^{137}$ Therefore, the clinical significance of nocturnal BP is attracting interest. The results of a large-scale intervention study ${ }^{139}$ and an international collaborative study of observation studies ${ }^{140}$ show that low nighttime and low daytime BP are considered to improve the prognosis of patients. For the future, a wide application of home BP-measuring devices is expected to evaluate the BP during sleep at night in relation to the quality of sleep and to diurnal changes in BP.

\section{9) HOME BP MEASUREMENTS IN VARIOUS DISEASES}

Home BP, measured by patients themselves over a long period, is widely used for the management of chronic diseases in which BP control has a critical role for the prognosis. The AHA/ASH/PCNA joint statement ${ }^{19}$ and ESH Guidelines for home BP measurements ${ }^{17}$ emphasize the importance of home BP measurements in the management of diabetes mellitus, pregnancy, children and renal diseases.

\section{Diabetes mellitus}

The International Diabetes Federation has recommended the use of home BP for the management of BP in diabetic patients. ${ }^{141}$

The J-HOME Study reported that home BP was $\geqslant 130 / 80 \mathrm{~mm} \mathrm{Hg}$ in $7 \%$ of diabetic patients in whom clinic BP was controlled under 130/80 mm Hg. ${ }^{142}$ Home BP in the morning has been reported to more accurately reflect target organ damage than clinic BP in diabetic patients. ${ }^{88,116,143}$ Management of patients on the basis of telemedicine in co-operation with nurses, where home BP is used as an index, has been reported to have led to a more rapid control of BP in diabetic patients. ${ }^{144}$

\section{Pregnancy}

Long-term and short-term changes in BP occur during pregnancy and after delivery. ${ }^{91}$ Home BP monitoring is the optimal method for the early detection of and early preventive intervention in preeclampsia and eclampsia. ${ }^{145}$ White-coat hypertension has also been frequently detected by home BP measurements in pregnant women. ${ }^{146,147}$
Changes in BP during pregnancy are markedly affected by the season. Seasons are important for the diagnosis of hypertension during pregnancy and preeclampsia. ${ }^{91,145}$

\section{Renal diseases (chronic kidney disease, dialysis)}

Renal diseases are often accompanied by hypertension, and hypertension is the greatest risk factor for the progression of nephropathy. In the general population, the risk of chronic kidney disease has been reported to be high in patients with masked hypertension, as determined by home BP measurements. ${ }^{148}$ In patients undergoing dialysis, the greatest prognostic factor is the presence of cerebroand cardiovascular complications, and the management of hypertension is extremely important. However, BP measured at the dialysis center fluctuates widely, and has been reported to not accurately reflect the outcome. Home BP is known to more closely reflect the usual BP of dialysis patients. ${ }^{149}$ In addition, home BP measurements in dialysis patients have been shown to improve the state of BP control. ${ }^{150,151}$

\section{Home BP in children}

As white-coat hypertension and masked hypertension have also been measured in children, home BP measurements are considered particularly useful for the diagnosis of hypertension. ${ }^{152}$ However, unlike adults, home BP in children has been reported to be higher than clinic $\mathrm{BP}$ or daytime $\mathrm{ABP}{ }^{152,153}$

\section{0) EFFECTS OF HOME BP ON THE MEDICAL ECONOMY}

The introduction of ABPM into the diagnosis and treatment of hypertension has been shown to have a strong effect on the medical economy. ${ }^{154,155}$ If home BP provides information comparable to that provided by ABP, it would also be expected to exert a great effect on the medical economy. ${ }^{156}$ In fact, in Japan, where home BP-measuring devices are already used by most hypertensive patients, the introduction of home BP into the care of hypertension has resulted in a decrease in annual medical expenditure of about 1 trillion yen. ${ }^{157,158}$ This decrease has been mediated primarily by screening for white-coat hypertension and masked hypertension. As a result of large-scale intervention studies, the introduction of home $\mathrm{BP}$ has also been reported to lead to a reduction in medical expenditure via a decrease in the amount of drugs used. ${ }^{67,77}$

\section{CHAPTER 2. DEVICE FOR SELF-BP MEASUREMENTS AT HOME}

\section{RECOMMENDATION 1}

Devices: Arm-cuff devices based on the cuff-oscillometric method validated on the basis of the auscultation method are recommended for home BP measurements.

Previously, mercury column manometers or aneroid manometers, in conjunction with the auscultation method, have been used for home BP measurements. However, these manometers, especially aneroid manometers, are sometimes unreliable and inaccurate. Mercury column manometers are cumbersome and cause environmental pollution. Furthermore, the auscultation method involves a subjective decision and a complex technique, and technical instruction and training are necessary to perform an accurate auscultation. For all these reasons, previous devices for home BP measurements were not widely accepted and, consequently, not widely distributed. 
In the 1960s, electrical devices based on the microphone method were introduced for home BP measurements. However, because of the mechanical properties of the microphone, these devices were costly and subject to frequent malfunctions. The microphone method also had an inherent shortcoming in determining the phase V Korotkoff sound, ${ }^{159}$ in that an auscultation gap made determination of DBP inaccurate. ${ }^{155,159}$ Thus, microphone devices for home BP measurements were not widely distributed.

During this period, theoretical analysis of the cuff-oscillometric principle advanced extensively. In 1969, Posey et al. ${ }^{3}$ discovered that the maximum oscillation of intra-cuff pressure was nearly identical to the mean arterial $\mathrm{BP}$, and the cuff-oscillometric principle was originally introduced as a method of determining mean arterial BP. Several experimental studies revealed that SBP and DBP could be estimated from the pattern of the gradual increase and decrease in cuff oscillation during cuff-pressure deflation. This basic algorithm has been improved by including procedures to correctly approximate the characteristic changes in cuff oscillation to the phase I and phase $\mathrm{V}$ Korotkoff sounds, and now almost all electrical devices for home BP measurements are based on the cuff-oscillometric principle.

However, the different properties of the Korotkoff sounds and cuff oscillation led to an unavoidable difference in BP values between the two methods. Nevertheless, devices based on the cuffoscillometric principle have become the norm for home BP measurements because of their simple mechanical properties, requiring only measurements in cuff-pressure changes. Therefore, these devices incorporate only a pressure sensor. Such a simple mechanism makes the device less troublesome and cheaper. The cuff-oscillometric device has another advantage when compared with the microphone device, in that surrounding noise does not interfere with BP measurements. More accurate BP values in patients with atrial fibrillation or arrhythmia are also available by cuff-oscillometric devices when compared with the Korotkoff sound method, as ectopically large or small pulses are averaged by the algorithm. Such factors encourage the production and distribution of cuff-oscillometric devices for home BP measurements. However, it is remarkable that sphygmomanometers used in the clinical setting have been changing from the Korotkoff sound method to cuff-oscillometric devices without much difficulty.

Although the mercury column sphygmomanometer with auscultation is becoming obsolete, the gold standard for clinical practice is still the Korotkoff sound method using a mercury column sphygmomanometer. Almost all epidemiological and clinical studies on hypertension have been based on casual-clinic BP measured by the Korotkoff sound method. Therefore, clinical and epidemiological information obtained using the cuff-oscillometric principle needs to be validated by the accumulation of data.

Various manufacturers of devices using the cuff-oscillometric principle may use different algorithms, leading to differences among devices in BP measurements from a single subject. In practice, the accuracy of automatic devices is determined by comparison with the auscultation method, and no other standard method is currently available for this purpose. The issue here is the subjectivity and the possible inaccuracy of auscultation when the auscultation method is used as a standard. To exclude the shortcomings of the auscultation method, equipment based on objective methods should be developed for the calibration of automatic devices, in which the Korotkoff sound signal is treated with an established algorithm, and cuffoscillometric devices are validated from this standard equipment. Objective and accurate evaluation of these automatic devices is a prerequisite for the authorization of cuff-oscillometric devices for home BP measurements. The accumulation of clinical and epidemiological data obtained by authorized cuff-oscillometric devices may finally validate such devices as tools for clinical decision making. As BP measurements in a clinical setting are now mostly obtained by cuff-oscillometric devices, the necessary data will be accumulated soon.

\section{CHAPTER 3. TECHNICAL INSTRUCTION: SITE FOR BP MEASUREMENTS, CUFF SIZE AND MEASUREMENT POSITION}

\section{RECOMMENDATION 2}

1. Site for BP measurements and arm for measurement:

BP should be measured essentially at the upper arm of the nondominant hand. When apparent $\mathrm{BP}$ differences between arms are observed, BP should be measured with the arm that shows the higher BP.

BP should be measured by keeping the arm cuff at heart level, with extension of the lower arm, and relaxation of the arm by means of a supporting pillow.

2. Cuff:

A soft arm cuff is usually recommended. In subjects with standard proportions, a hard plastic cuff is also applicable. In subjects with excessively thick or thin arms, large cuffs or small cuffs, respectively, should be used.

\section{1) SITE FOR BP MEASUREMENTS AND ARM FOR MEASUREMENT}

The cuff oscillometric principle is applicable to any site where an arterial pulse is available. However, the standard site for BP measurements is the upper arm, and several issues arise when BP is measured at sites other than the upper arm.

At present, three types of electrical devices for home BP measurements are commercially available: the arm-cuff device, the wrist-cuff device and the finger-cuff device. In 1999, 7 million of these electrical devices were produced in the Far East (including Japan, Korea and Taiwan), which represents $85 \%$ of the world production. Of those, $35 \%$ were wrist-cuff devices. ${ }^{13}$ Previously, finger-cuff devices commanded a considerable portion of the market share owing to their convenience and ease of use. However, it is now known that finger BP is physiologically different from brachial BP, and issues of vasospasm in the winter season as well as hydrostatic pressure differences are inevitable. Therefore, manufacturers have decreased production of finger-cuff devices and extensively increased production of wrist-cuff devices. In Japan wrist-cuff devices have 35\% of the market share, ${ }^{13}$ and in Germany they possess almost half of the market share. Wristcuff devices are much easier to handle and more portable, but have several serious shortcomings. The most important issue is the necessity for correction of the hydrostatic pressure. The reference level for $\mathrm{BP}$ measurements is the right atrium. When the measurement site is $10 \mathrm{~cm}$ below the right atrium, SBP and DBP are measured as $7 \mathrm{~mm} \mathrm{Hg}$ higher than at the level of the right atrium, and vice versa. Therefore, instructions for the wrist-cuff device indicate that the wrist must be kept at heart level. However, it is uncertain whether general users can accurately recognize where the heart level is. For example, the apex of the heart is sometimes determined as the heart level, but it is actually $5-10 \mathrm{~cm}$ lower than the right atrium, resulting in a $3.5-7-\mathrm{mm} \mathrm{Hg}$ higher BP reading compared with a measurement taken at the right atrium level. A 10-cm difference from the right atrium level easily and frequently occurs in usual settings. This difference may have serious 


\section{Table 2 Measurement of home blood pressure}

1. Devices based on cuff-oscillometric method using upper arm cuff

2. Environment for measurement

1) Under quiet circumstance and appropriate room temperature ${ }^{a}$

2) Sitting on the chair with a support for the back without legs crossed and after 1-2-min resting (cross-legged sitting or upright sitting is also permitted)

3) Without conversation during measurement

4) Restriction against smoking, drinking alcohol, caffein containing beverage before measurement

5) Circumstance where upper-arm cuff can be set on the heart level

6) Permission to attach the arm-cuff on thin clothes

3. Measurement conditions

1) Essential conditions

a. Morning: within $1 \mathrm{~h}$ after waking up, after urination, before dosing in the morning, before breakfast, after 1- to 2-min resting in a sitting position

b. Night: before retiring, after 1- to 2-min resting in a sitting position

2) Selection conditions

a. According to instructions: before dinner, before dosing in the evening, before bathing, before drinking alcohol

b. Others (if necessary): in the presence of symptoms, during the daytime on holidays; during sleep at night ${ }^{b}$

4. Frequency of measurement: one to three times per occasion ${ }^{c}$

5. Measurement period: as long as possible

6. Recording: all values should be recorded

a Especially in the winter season, measurement under the circumstance without heating elevates blood pressure. Alert to note room temperature during measurement in the winter season.

${ }^{b}$ Devices, which can measure blood pressure during sleep are now available.

${ }^{c}$ Many measurements should not be requested.

Note 1: In patients who are anxious about home blood pressure measurement, it should be avoided.

Note 2: Physicians must explain to the patients that they should not emotionally overcome by Note 2: Physicians

individual values. measurements.

From JSH 2009 guidelines (modified partly).

implications for public health policies as well as clinical practice. In this situation, when the wrist is settled on the chest at the site of the heart in the supine position, the wrist is sometimes laid at a level $5-10 \mathrm{~cm}$ higher than that of the heart level, leading to lower BP measurements by $3.5-7 \mathrm{~mm} \mathrm{Hg}$ than $\mathrm{BP}$ measurements at the right atrium. This issue also applies to the arm-cuff device, and adequate instruction is necessary when home BP is measured by the arm-cuff device.

Even after appropriate correction of the hydrostatic pressure in the wrist-cuff device, another issue remains concerning the anatomy of the wrist. At the wrist, the radial and ulnar arteries are surrounded by the radial bone, ulnar bone and several long tendons, including the long palmar tendon. Therefore, even a sufficient excess of cuff pressure over arterial pressure does not necessarily occlude these arteries completely. ${ }^{160}$ Measurements are also influenced by flexion and hyperextension of the wrist. ${ }^{160}$ As a result, wrist-cuff devices sometimes provide erroneous readings, especially for SBP. At present, the wristcuff device is inappropriate as a tool for clinical decision making. Recently, a wrist-cuff device that does not work unless the device is at the heart level has been developed, ${ }^{161}$ but even such devices do not overcome this anatomical issue. However, the wrist-cuff device has a certain merit in terms of convenience. Arm-cuff devices also have some shortcomings, such as application to a thick arm, the relationship between the cuff and clothes and the position of the arm cuff in relation to the elbow joint. The wrist-cuff device can overcome these shortcomings. However, this Working Group recommends the use of an arm-cuff device operated under standard measurement procedures. In general practice, BP differences between arms must be evaluated.
Self-BP measurements at home, however, are usually performed using the non-dominant arm. When an apparent difference in BP is observed between the arms in a clinical setting, the arm showing the higher BP should be used for self-BP measurements. To provide consistent results, the same arm should always be used for self-BP measurements.

Instructions concerning the standard measurement method are indispensable. The standard measurement method is based on the measurement method of clinic BP described in the Japanese Society of Hypertension Guidelines for the Management of Hypertension, $2009,{ }^{20}$ including keeping the arm cuff at heart level, extension of the lower arm, relaxation of the arm by means of a supporting pillow, cuff size, the relationship between the cuff and clothes, and the relationship between the cuff and the elbow joint. Cuff attachment over a shirt with thin cloth is permitted, whereas that over a shirt with thick cloth or a jacket causes substantial measurement errors. Measurement procedures specified for home BP are listed in Table 2.

\section{2) CUFF}

At present, soft cuffs and hard plastic cuffs are available for automatic arm-cuff devices for home BP measurements. In individuals with thick arms, a hard plastic cuff does not necessarily fit the arm, resulting in erroneous measurements. Thus, a soft cuff is more suitable, but in certain subjects a hard plastic cuff is convenient and measures BP accurately. Among cuff-oscillometric devices, the width and length of the cuff bladder differ among producers. This is permitted by the American Association for Medical Instrumentation (AAMI) ${ }^{162}$ and the American National Standard Institute Inc. (ANSI) ${ }^{163}$ as a prerequisite, provided that cuff pressure is transmitted to the artery and can occlude the brachial artery completely.

In individuals with excessively thick or thin arms, the use of large or small cuffs, respectively, is recommended.

\section{CHAPTER 4. VALIDATION OF THE DEVICE}

\section{RECOMMENDATION 3}

Validation of the device: Devices for home BP measurements should be adapted to AAMI standards and BHS guidelines. Furthermore, the difference between the auscultatory method and the device should be within $5 \mathrm{~mm} \mathrm{Hg}$ in each individual. For validation of the device, simultaneous measurements using bilateral arms or sequential measurements using one arm are applicable. Home measurement devices should be validated before use and at regular intervals during use.

The pressure sensors incorporated into recent devices for self-BP measurements are semiconductor sensors. The linearity, durability and accuracy of these sensors are superior to those of the strain sensors used previously. Strain sensors required validation with standard mercury column manometers, but this procedure is not necessary with semiconductor sensors. Indeed, there are no standard mercury column manometers available for clinical settings. Mercury column measurements used in clinical practice are subject to several factors that may disturb their accuracy. Thus, validation of semiconductor pressure sensors with an inaccurate mercury column manometer sometimes leads to erroneous results.

There are two reasons for validation of the device. The first is to confirm whether the type of device is clinically applicable for BP measurements in the general population, and the other is to confirm whether the device can accurately and properly measure BP in individuals. 
Previously, validation of a device was performed by simultaneous measurements using a mercury column manometer and the device itself, both of which were connected to the arm cuff of the device by a Y-tube, followed by determination of the difference between these two readings. However, this method has recently encountered a serious problem. Several guidelines have specified the deflation rate of the cuff pressure to be $2-3 \mathrm{~mm} \mathrm{Hg} \mathrm{s}^{-1}$ or beat. ${ }^{164}$ However, recent cuff-oscillometric devices deflate by $5-7 \mathrm{~mm} \mathrm{Hg} \mathrm{s}^{-1}$ or beat. In the cuff-oscillometric method, it is possible to deflate the cuff rapidly, as SBP and DBP are determined by an algorithm that calculates BP from the increase and decrease in cuff pressure. Such a rapid deflation is considered to be one of the advantages of the device because of the lower physical burden for subjects. Therefore, simultaneous measurements using the auscultation method with a mercury manometer cause a large systematic error in the determination of SBP and DBP; the measured SBP is lower and the measured DBP is higher during rapid deflation than during standard deflation. Thus, it is difficult to measure BP effectively using the simultaneous method. To overcome this problem, the device should incorporate a calibration mode, wherein the deflation speed is limited to $2-3 \mathrm{~mm} \mathrm{Hg} \mathrm{s}^{-1}$ or beat. However, changes in the deflation speed make it necessary to use a different algorithm to determine SBP and DBP. Therefore, at present, it is impossible to apply the simultaneous method to validate these devices.

The currently recommended method is the sequential method. In this method, BP measurements with the standard auscultatory method and the device are performed sequentially on the same arm, and the difference in BP between the two methods is calculated. The International Protocol for the validation of BP-measuring devices in adults proposed by the European Society of Hypertension recommends this method, with the preferred number of measurements being four by auscultation and three by the device. ${ }^{15,165}$ These guidelines also recommend at least two measurements by auscultation and two measurements by the device for validation in a practical setting.

Simultaneous measurement using bilateral arms is superior from the viewpoint of simultaneousness, but BP differences between the right and the left arms affect the validation results. To overcome this problem, a simultaneous measurement using both arms should be performed, in which initially the auscultatory method is used on one side and the tested device is used on the other side. Then, each measurement is done using the contralateral arm. The differences in measurements by auscultation and by the device are averaged. At least two simultaneous measurements are necessary to cancel BP differences between arms. This sequential measurement method is used worldwide for validation.

When a wrist-cuff device is used, validation by the simultaneous method using both arms or by the sequential method using one arm is indispensable.

Validation as to whether a type of device is clinically applicable for BP measurements in the general population has been performed in specialized institutes for that purpose, and has included a certain number of subjects with wide BP ranges and ages. ${ }^{15,162,165}$ The auscultatory method may remain unchanged as the gold standard, although the issue of the subjectivity of auscultation will also remain. In the future, an international standard device will be developed, and validation will be performed by the differences between the standard device and the tested device. In general practice, however, validation of whether a device can accurately and adequately measure BP in individuals will be done using the auscultatory method. In recent years, 3.5 million automatic devices for self-BP measurements have been sold annually in Japan, ${ }^{166}$ and a total of 35 million devices have already been distributed. Therefore, a serious clinical and epidemio- logical issue exists as to whether a home BP measurement device can provide an individual's BP accurately, and thus validation of the device is very important for clinical practice, as well as for public health. However, it should be noted that validation of the device is not necessarily performed properly in a medical setting because of an absence of proper information on the validation procedure and a lack of financial support for validation from medical insurance. This Working Group emphasizes the need for financial support from medical insurance for the validation of automatic devices.

In the British Hypertension Society (BHS) guidelines for the validation of automated devices, devices for which a high proportion of BP measurements differ from the auscultatory method by $<5 \mathrm{~mm} \mathrm{Hg}$, in particular, have been evaluated. ${ }^{167}$ Thus, a device that differs from the auscultatory method by $<5 \mathrm{~mm} \mathrm{Hg}$ is evaluated as accurate and suitable for a particular subject. However, it is uncertain whether this device is also suitable for other subjects unless validation has been performed. The AAMI states that a particular type of device is clinically applicable for self-BP measurements when the mean difference from the auscultatory method is $<5 \mathrm{~mm} \mathrm{Hg}$ and the s.d. of the mean difference is $<8 \mathrm{~mm} \mathrm{Hg} .{ }^{162}$ Thus, a maximal $13 \mathrm{~mm} \mathrm{Hg}($ mean+s.d.) difference from the auscultatory method in each subject is approved on the basis of this standard, suggesting that devices conforming to AAMI guidelines do not necessarily provide a proper BP value in individuals. It should be emphasized again that there are different purposes for validation, including applicability to the general population and suitability of the device for an individual. In these guidelines, we recommend a device for practical use when the difference in BP from the auscultatory method is $<5 \mathrm{~mm} \mathrm{Hg}$ in a particular subject. Obviously, the device should be adapted to AAMI standards and BHS guidelines.

Home measurement devices should be validated before use and at regular intervals (essentially once a year) during use.

The results of tests for the accuracy of various home BP-measuring devices are provided at www.dableducational.org and http:// www.bhsoc.org/blood_pressure_list.stm.

\section{CHAPTER 5. MEASUREMENT PROCEDURE}

\section{RECOMMENDATION 4}

Measurement procedure: Home BP should be monitored under the following conditions:

(1) In the morning within $1 \mathrm{~h}$ after waking, after micturition, in sitting position after 1-2 min of rest, before drug ingestion and before breakfast.

(2) In the evening just before going to bed, sitting after 1-2 min of rest.

ABPM provides $B P$ values measured every $15-30$ min in relation to time and daily activity on a particular day, and thus the control of measurement conditions is not appropriate for ABPM. Conversely, home BP measurements characteristically provide BP values under controlled conditions that should remain as stable as possible for a long period of time. The JNC-VII, ${ }^{9}$ the 1999 WHO-ISH Guidelines ${ }^{10}$ and the ESH-ESC Guidelines ${ }^{18}$ emphasized the clinical significance of self-BP measurements at home. However, these guidelines do not refer to standardization of the measurement procedure for home BP. Only the JSH2009 Guidelines specified standards for the measurement procedure. ${ }^{20}$ Home BP measurements have been shown to vary with various environmental factors. ${ }^{168}$ The American Society of Hyperten- 
sion Ad Hoc Panel recommended BP measurements at home on holidays as well as working days. ${ }^{169}$ The timing of daily measurements also extensively affected home BP values. ${ }^{169}$

This is an appropriate time to review the characteristics and purpose of home BP measurements. All guidelines and recommendations emphasize the good reproducibility and reliability of home BP. These characteristics arise from the ability to make multiple measurements over a long period of time. Home BP measurements are suitable to assess the effect and duration of the action of antihypertensive drugs, and for the diagnosis of intractable hypertension and white-coat hypertension. Furthermore, morning hypertension has recently been attracting attention as a risk factor for cardiovascular morbidity and mortality. Although ABPM can also provide information on hypertension in the morning, ${ }^{170}$ home BP measurements are the only practical method to obtain BP in the morning. Recently, masked hypertension has also been attracting attention in relation to morning hypertension. This concept is defined as normal clinic BP $(<140 / 90 \mathrm{~mm} \mathrm{Hg})$ with home BP indicating hypertension ( $\geqq 135 / 85 \mathrm{~mm} \mathrm{Hg}$ ). Masked hypertension determined by home $\mathrm{BP}$ in the morning is mediated, at least in part, by the insufficient duration of action of antihypertensive drugs. From this viewpoint, if the reproducibility and reliability of home BP measurements can be increased and BP information, except in the morning and evening, is available, the clinical significance of these measurements would improve extensively. However, at present no standard exists for the measurement procedure of home BP.

As mentioned in the previous chapter, the most important feature of home BP measurements is long-term and repetitive measurements using arm-cuff devices under controlled conditions. In this respect, compliance or adherence to home BP measurements is a very important issue. Thus, BP measurements per se should be the first priority. However, to increase the clinical significance and comparability of home BP measurements as a component of clinical decisionmaking, the establishment of a standardized procedure for home BP measurements is essential.

Recently, the guidelines for home BP measurements or BP measurements outside of a clinical setting have been published in Western countries. ${ }^{14,17,19}$ Before these guidelines, the JSH published guidelines for self-monitoring BP at home in $2003^{13}$ and the JSH 2009 Guidelines for the Management of Hypertension elaborated on the procedure for home BP measurements. ${ }^{20}$ The JSH Working Group for home BP measurements revised the 2003 guidelines for self-monitoring of blood pressure at home, wherein the principal policy of the 2003 guidelines was followed and the Western guidelines were partly referred to.

First of all, home BP should be measured at least twice daily, in the morning and in the evening. This is a requirement of almost all existing guidelines.

\section{1) MEASUREMENT PROCEDURE IN THE MORNING}

In the present guidelines, morning is defined as the time within a few hours after waking, that is, the time between waking and about $1000 \mathrm{~h}$. The Working Group recommends that measurements should be performed within $1 \mathrm{~h}$ of waking. This condition is not necessarily strict enough. However, the most important point in home BP measurements is that subjects measure their own BP at home for a long period of time. Consequently, a strict regulation of the timing within measurements may disturb the compliance or adherence to home BP measurements. The period within $1 \mathrm{~h}$ of waking includes several potential factors that modify BP, and thus the several conditions mentioned below must be considered. (In shift workers, $1 \mathrm{~h}$ after waking is not necessarily morning. In this case, the timing of
$1 \mathrm{~h}$ after waking may be kept as a condition, but the measurement time must be recorded.)

\section{After micturition}

In general, one urinates soon after waking. Before micturition, expansion of the urinary bladder elevates $\mathrm{BP}$, and after micturition, BP decreases. ${ }^{171}$ The measurement condition of micturition in the morning after waking ensures a consistent physiological background.

\section{Sitting position after $1-2 \mathrm{~min}$ of rest}

A sitting position is the common position for BP measurements in all existing guidelines. In Japanese people, a sitting position includes cross-legged sitting or upright sitting, and in the present guidelines, the sitting position depends on one's usual custom. When a sitting position is not available, measurement in a recumbent position is also permitted.

In general, many guidelines recommend $5 \mathrm{~min}$ of rest before measurement. ${ }^{8-12,14-20}$ However, the present guidelines propose a more practical and generous condition to maintain adherence to home BP measurements, namely, taking BP measurements after 1-2 min of rest. The Subcommittee of Professional and Public Education of the American Heart Association Council on High Blood Research recommended 3-5 min of rest before home BP measurements. ${ }^{14}$ This recommendation is almost similar to that of the JSH guidelines. ${ }^{20}$

\section{Before taking antihypertensive drugs}

One of the most important purposes of home BP measurements is evaluating the duration of the effect of antihypertensive drugs. Morning BP measurements before taking the next dose of an antihypertensive drug represents a 'trough' effect of the drug. Evaluating the trough effect allows a definition of the duration of action of the drugs. ${ }^{60}$

Recently, morning hypertension has been attracting attention, and some antihypertensive drugs are administered just after waking to control morning hypertension. In such cases, BP measurements before drug ingestion are recommended, although measurements 5-10 min after drug ingestion are also permitted. In the present guidelines, additional measurements before the evening dose are also recommended to evaluate the effect of antihypertensive drugs according to the JSH 2009 Guidelines ${ }^{20}$ (Table 2 in Chapter 3).

\section{Before breakfast}

Among daily habitual behaviors, dietary routine affects BP most extensively. BP generally increases during a meal and decreases after the meal. To exclude such variability, BP measurements before breakfast are recommended. Additional measurements before supper are also recommended (Table 2 in Chapter 3).

\section{2) MEASUREMENT PROCEDURE IN THE EVENING}

Controlling the timing of the evening measurement is more difficult than that in the morning. Clinical pharmacology studies to determine the effect or duration of action of a drug often require BP measurements to be taken before supper, before drinking alcohol, before taking a bath or before taking a drug. However, in normal daily life in Japan, it is difficult to request patients to follow such conditions. To evaluate the antihypertensive effect and duration of action of this effect, the present guidelines settled for additional measurement conditions, such as before supper and before the evening dose.

To improve the adherence to home BP measurements, only a single condition, that of measurements just before bedtime, has been 
proposed. In general, Japanese men take an alcoholic beverage and a bath at about this time. These factors usually decrease BP. ${ }^{114,120}$ In the Ohasama study, in which evening BP was measured under the abovementioned conditions, BP in the morning was a few $\mathrm{mm} \mathrm{Hg}$ higher than that in the evening. ${ }^{121}$ This was especially true in the hypertensive population of Ohasama, for whom the difference in SBP was 10$20 \mathrm{~mm} \mathrm{Hg} .{ }^{119}$ Such differences were also confirmed in Western countries, while several reports confirmed a higher home BP in the evening than that in the morning. ${ }^{128,129}$ This may reflect the differences in lifestyles between Japanese and Western populations. When a longacting antihypertensive drug is administered once in the morning, BP in the evening corresponds to near the peak effect. Recently, the ratio of the morning effect to the evening effect has been used as an indicator for the duration of action of the antihypertensive effect, the morning $v s$. evening ratio. This concept is derived from the trough $v s$. peak (T/P) ratio obtained from ABPM..$^{59,60}$ To control hypertension in the morning, antihypertensive drugs have recently begun to be administered in the evening or just before bedtime. In this case, BP in the morning corresponds to near the peak effect and BP in the evening to near the trough effect. Thus, the duration of action of the antihypertensive effect is expressed as the evening $v s$. morning ratio. Furthermore, in the present guidelines, additional measurements before supper, before the evening dose, before taking a bath and before drinking alcohol are recommended according to the JSH 2009 Guidelines $^{20}$ (Table 2 in Chapter 3).

\section{3) MEASUREMENT AT MIDNIGHT}

Recently, a new home BP device incorporating an integrated circuit memory and timer has been developed (HEM-747 IC-N, HEM-7080 IC-N, Omron, Kyoto, Japan)., ${ }^{730-133}$ This device is being used in a large-scale interventional study in Japan using home BP measurements and the internet, known as the Hypertension Objective Treatment Based on Measurement by Electrical Device of Blood Pressure (HOMED-BP) study. ${ }^{172}$ In this study, devices are preset to work automatically at $0200 \mathrm{~h}$, as the nadir of nocturnal BP was observed at around $0200 \mathrm{~h}$ in the Ohasama study population. ${ }^{174}$ Using this device, set to work once at $0200 \mathrm{~h}$, the subject can recall after waking the quality of sleep during the measurement. On the other hand, it is impossible to evaluate the quality of sleep during ABPM, as one cannot define the quality of sleep during measurements every $30 \mathrm{~min}$. Although determination of nocturnal BP by home measurement devices is not yet widespread, this procedure is significant for determination of circadian BP variations and nocturnal BP levels.

\section{4) MEASUREMENT IN THE WORKPLACE OR DURING DAILY ACTIVITIES}

Although portable devices allow self-BP measurements in the workplace or during daily activities, in practice such measurements are difficult. In the future, development of accurate and reliable wrist-cuff devices may permit BP measurements under stressful circumstances. The importance of measurements in the workplace or under stressful circumstances was emphasized by Pickering. ${ }^{14,19}$ Elevations in BP in the workplace or under stressful conditions mediate masked hypertension. ${ }^{173}$

\section{5) MEASUREMENT IN SUBJECTS WITH ARRHYTHMIA}

It is often difficult to obtain accurate BP measurements in subjects with arrhythmia. Even in self-BP measurements, it is necessary to exclude the effect of arrhythmia with repetitive measurements, usually more than three times.
In patients with atrial fibrillation, accurate measurements are often difficult, but approximate values of SBP and DBP can be obtained by the cuff-oscillometric method, unless patients have bradycardia and the smoothness of consecutive pressure waves are lost. ${ }^{175}$

\section{6) MEASUREMENT IN CHILDREN}

At present, clinical studies on hypertension in children are based on BP measurements with the cuff-oscillometric method. However, validation of devices based on the cuff-oscillometric method in children has not been systematically performed and the description in the present guidelines essentially targets adults. There is no issue in applying the usual devices for adults to children with adult physique.

\section{7) MEASUREMENT IN PREGNANT WOMEN}

Self-BP measurement at home is very important for pregnant women and may become indispensable for the diagnosis and treatment of pregnancy-induced hypertension. However, devices for home BP measurements specifically for pregnant women are rare. Most devices for home BP measurements are not validated in pregnant women and thus, the accuracy of home BP values in pregnant women are not guaranteed, whereas in clinical practice, pregnant women are equated to ordinary adults and home BP is measured with generally used home BP devices.

\section{CHAPTER 6. NUMBER OF MEASUREMENTS AND DURATION OF THE MONITORING PERIOD}

\section{RECOMMENDATION 5}

Number of measurements and duration of the monitoring period

1. Home BP should be measured 1-3 times each in the morning and evening.

2. Home BP should be measured over as long a period as possible.

3. The observation period (before the beginning of medication): If, in the clinic, SBP is $\leqslant 179 \mathrm{~mm} \mathrm{Hg}$ and DBP is $\leqslant 109 \mathrm{~mm} \mathrm{Hg}$ (grade II or milder hypertension), BP should be measured at least 5 days a week. The observation period should be 1-2 weeks depending on the situation. If, in the clinic, $S B P$ is $\geqslant 180 \mathrm{~mm} \mathrm{Hg}$ or DBP is $\geqslant 110 \mathrm{~mm} \mathrm{Hg}$ (grade III hypertension), treatment should be initiated promptly, or home BP should be measured for 1-3 days according to the judgment of the physician.

4. Stable period (period of satisfactory BP control):

Home BP should be measured at least 3 days a week.

5. Period of drug titration: Home BP should be measured at least 5 days a week.

Problems that remain controversial are how many times home BP should be usually measured in the morning and evening, and how long thereafter measurements should be continued. The answers to these questions vary depending on the objective of home BP measurements, but the present guidelines propose the most convenient method, which includes the number and duration of home BP measurements appropriate for common evaluation.

Guidelines by the International Consensus Meeting $2000^{175}$ stated that 'The frequency of measurement naturally varies depending on the purpose and indications and objectives,' and recommended that measurements be taken two times each in the morning and evening on 3 working days ( 12 times per week). The frequency of measurements should also be modified according to the severity of hypertension, whether measurements are taken before or during medication, and the timing of changes in drugs or changes in the dose of drugs. 
Pickering ${ }^{168}$ proposed that BP should be measured as frequently as possible during the early period of diagnosis, but also suggested that the frequency of measurements may be reduced after BP has been relatively controlled. He recommended BP measurements 3 times each in the morning and evening 3 days a week (18 times/week) for at least 2 weeks in newly diagnosed patients. ${ }^{168} \mathrm{He}$ also urged increases in the frequency of measurements if antihypertensive medication had been newly initiated, or the dose or class of the antihypertensive drug had been changed. Recommendations of measurement frequency on one occasion in recent Western guidelines vary; some recommend two to three measurements on each occasion on 7 days, ${ }^{14-19}$ others recommend at least one measurement at each point on 6-7 days, ${ }^{176}$ whereas some others do not mention the number of measurements. ${ }^{9,18}$ Therefore, there is no consensus as of yet.

As for the Japanese guidelines, both the Guidelines for Home BP Measurement published in 2003 and the JSH $2009^{20}$ recommended one to three measurements on each occasion, but a single measurement on each occasion was essentially permitted. The guidelines also proposed the use of the mean value of the first measurements among multiple measurements on each occasion on 5-7 days for BP evaluation. They recommended continuous measurements over as long a period as possible, with recording of all values in a log book, but stated that excessive measurement frequencies on one occasion were unfavorable.

Many of the Western guidelines recommended two measurements each in the morning and evening on the basis of the report by Stergiou et al. ${ }^{177}$ that home BP values on multiple measurements at each point exhibited a regression to the mean. Such decreases in home BP with repeated measurements on one occasion had been observed previously. According to a study in healthy individuals by de Gaudemaris et al., ${ }^{178}$ home BP values were highest on the first and lowest on the third of three measurements, and the difference between measurements in systolic BP and diastolic BP was 3 and $2 \mathrm{~mm} \mathrm{Hg}$, respectively.

However, Kawabe et al. ${ }^{179}$ reported that the value increased from the first to the second measurement, and from the second to the third in $30-40 \%$ of those who measured home BP repeatedly on one occasion. Such a phenomenon is often observed in daily clinical practice. By a series of studies on the reproducibility and frequency of measurement of home BP, Kawabe et al. reported that the mean value of the first measurements on each occasion for a certain period and the mean value of multiple measurements on each occasion were both highly reproducible, ${ }^{180}$ that a single measurement over 7 days was clinically sufficient, ${ }^{180}$ that the mean value of the first measurements on each occasion for a certain period was higher than the mean value of the second or third measurements during the same period, and that the mean value of the first measurements on each occasion was appropriate for the screening of hypertension. ${ }^{181}$

Moreover, a report by van der Hoeven et al. concerning the adherence to measurement instructions demonstrated the difficulty in maintaining multiple measurements on one occasion and the use of mean values for $\mathrm{BP}$ evaluation. Adherence to the instruction of measuring BP two times each in the morning and evening over 7 days was $66 \%,{ }^{182}$ which indicated a difficulty in maintaining BP measurements always two times (or more) on one occasion.

On the basis of this evidence, the present guidelines recommend one to three measurements of home BP on one occasion, meaning that a single measurement is acceptable. The differences in $\mathrm{BP}$ values on a series of multiple measurements indicate the inherent variability of BP, and may include a defense reaction to self-measurement (a kind of white-coat phenomenon). Such a variation is considered to be a characteristic of BP in that individual. Therefore, as discussed in the next chapter on 'recording', it is desirable to record all values of home $\mathrm{BP}$ in the log book when multiple measurements on each occasion are performed.

Regarding the duration of the monitoring period, setting a particular period is considered unnecessary for home BP measurements. A characteristic of home BP measurements is that a large amount of data can be collected over a long period of time. Therefore, hypertensive patients are recommended to measure home BP in the morning and evening for a long period of time. However, caution is needed, as asking for compulsory daily measurements occasionally reduces adherence. ${ }^{182}$ As self-monitoring of BP provides health-related information useful for modifications in lifestyle and health management, and leads to improvements in the adherence to antihypertensive medication, ${ }^{82,83}$ life-long monitoring is recommended. For individuals with borderline hypertension and normotensive individuals, regular weekly or monthly measurements are recommended.

Setting the number of measurements is indispensable for the use of home BP data for clinical pharmacological evaluation and the diagnosis and treatment of hypertension. Therefore, we recommend the following for the number and period of measurements: Before the initiation of medication, if clinic SBP is $\leqslant 179 \mathrm{~mm} \mathrm{Hg}$ and DBP is $\leqslant 109 \mathrm{~mm} \mathrm{Hg}$ (< grade II hypertension), home BP should be measured on at least 5 days during a 7 -day period. The observation period should be 1-2 weeks depending on the situation. If clinic $\mathrm{SBP}$ is $\geqslant 180 \mathrm{~mm} \mathrm{Hg}$ or DBP is $\geqslant 110 \mathrm{~mm} \mathrm{Hg}$ (grade III hypertension), treatment should be started promptly or home BP should be monitored for 1-3 days depending on the physician's decision. During a stable period with satisfactory control of BP, measurements should be performed at least 3 days a week. When the drug is changed, home BP should be measured on at least 5 days during a 7-day period. This recommendation about the frequency and period of measurement is based on the results of a study on the reproducibility and placebo effect of home BP measurements in untreated hypertensive patients in the Ohasama Study and 214 patients at a general hypertension clinic. The reproducibility of home BP on a single measurement in the morning averaged for 5 days, excluding the first 3 days of an 8-day observation period, was highly satisfactory $(\triangle \mathrm{SBP} /$ $\Delta \mathrm{DBP}=1.9 \pm 7.0 /-1.4 \pm 4.8 \mathrm{~mm} \mathrm{Hg}$, mean \pm s.d. $)$, and no placebo effect was noted. ${ }^{56}$

\section{CHAPTER 7. DOCUMENTATION}

\section{RECOMMENDATIONS 6}

Documentation: It is recommended that all home BP measurements should be documented without selection, together with pulse rate, the date and the time of measurements. Use of devices with a printer or an integrated circuit memory is useful to rule out selection bias.

All home BP measurements should be documented without selection. This will help to prevent overestimation or underestimation of home $\mathrm{BP}$ values. Mengden et al. ${ }^{183}$ reported that, among subjects who measured home BP, excess reports, insufficient reports and even reports of phantom records were frequently observed. Therefore, the best way to rule out biases is to use equipment incorporating an integrated circuit memory. However, a personal computer is currently needed to read out the memory, and thus this function may not necessarily work efficiently for all general users and practitioners. Furthermore, discrimination among data from multiple users is not possible with the present form of the device; therefore, a separate 
device is required for each user, and each user must be informed that the device is for their personal use only.

Among other methods to exclude selection bias, devices with a printer are sometimes useful, although selection bias cannot really be excluded using a printer, as subjects cannot be relied upon to consistently print all results. Therefore, subjects' documentation on worksheets still remains the most popular method to record home BP values. In this case, subjects must be instructed that all measurements, together with pulse rate, the date and the time of the measurements should be documented.

Recently, many pharmaceutical companies have begun to distribute worksheets for the recording of home BP, although the formats of these worksheets are inconsistent. For example, some of these forms ask subjects to record the trend of BP, and others ask for numerical information. Both types of information are useful for clinical practice, but recording of numerical information is more important. Numerical information should be recorded, as the trend is always available once there is numerical information. The worksheet should include spaces for year, month, day, clock time, BP and pulse rate. Spaces for morning values, daytime values and evening values should also be included. A reference column is useful to record episodes of daily life. A duplication function of worksheets is required so that the information can be available both at clinics/ institutions and for subjects.

\section{CHAPTER 8. DATA PROCESSING AND EVALUATION}

\section{RECOMMENDATION 7}

Data for processing and evaluation:

Home BP is evaluated using the mean values of single measurements in the morning and evening, averaged for a certain period (at least for 5 days before treatment, at least for 3 days in the stable period (period of satisfactory BP control) and at least for 5 days in the drug titration period). As all recorded values are evaluated, it is necessary to record all measured values. It is also desirable to simultaneously calculate the mean and standard deviation.

In practice, evaluations using the mean value of multiple measurements on each occasion during a certain period are also possible. However, it must be remembered that the mean value of all values on each occasion during a certain period may be lower than that of the first values on each occasion during that period. It is also practically possible to evaluate the mean value of all values measured in the morning and evening all together. Antihypertensive treatment is usually constructed according to the mean values on the first measurement averaged for a certain period. However, if a large variation in home $\mathrm{BP}$ on repeated measurements on each occasion is observed, home BP on the second and third measurements on each occasion should also be paid attention in order to prevent excessive decreases in BP by the treatment.

Before evaluation of home BP data, a condition for data processing should be confirmed. As discussed in Chapter 6, as home BP is measured in the morning and evening over a long period of time, home BP should be expressed as the mean and standard deviation over this period. As home BP in the morning and evening differ depending on environmental factors and physiological conditions, their clinical significance is assumed to be different. Therefore, morning and evening home BPs should be processed independently.

Here, the issue of how many times home BP should be measured on each occasion rises again. The number of measurements on one occasion may vary among institutes or according to the decision of the patients themselves. As the first measurement can be obtained under every measurement condition, comparisons among data obtained from different institutes and different patients for clinical and epidemiological studies should be based on the mean value of the first values on each occasion averaged over a long period. In the Ohasama Study, home BP on a single measurement in the morning on one day was reported to have more prognostic significance than the mean clinic BP of two measurements, and the mean value of home BP over 21 days (21 measurements) had even more prognostic significance. ${ }^{34}$ The clinical significance of home BP has been markedly improved by calculating the mean over a long time, even when the measurement frequency is once on one occasion. ${ }^{34}$ Also, in the Finn Home Study, home BP was measured in 464 subjects two times each in the morning and evening for 7 days. There was little difference between the mean values on the first and seventh days. The relationship between home BP and target organ damage was enhanced, with an increase in the number of measurements from which the mean value was calculated. There was no difference in the relationship between the mean value and target organ damage when the mean value was calculated from the sum of the first and second measurements on each occasion or from the values on the second measurements alone, suggesting that the values on the first and second measurements equally reflect organ damage. ${ }^{42}$ In the Didima Study in Greece, home BP was measured in 662 subjects two times each in the morning and evening for 3 days, and the relationship between home BP and the outcome was evaluated during an 8.2-year follow-up period. As a result, the mean value of the first measurements on each occasion was higher than that of the second measurements, but the prognostic significance of these two mean values was comparable. ${ }^{128}$

These results support the concept of the use of the mean value of the first measurements on each occasion for the evaluation of home $\mathrm{BP}$ and also support the method recommended by the present guidelines and the JSH 2009.

Therefore, a single measurement of home BP on each occasion and taking the average of home BP values on the first measurement on each occasion for a certain period is enough for the diagnosis and treatment of hypertension. ${ }^{184}$

The present guidelines recommend evaluation of the mean of the values on the first measurement on each occasion as the minimum requirement. Such a requirement ensures an improvement in the adherence to the measurement, elimination of various biases and enhancement of the convenience for not only subjects but also practitioners who evaluate BP values. Furthermore, the first measurement on each occasion can be obtained in every institution and by all subjects, and this common feature of measurements is of great value in medical judgments.

Moreover, a single measurement in the morning and evening was adopted by several epidemiological studies that provided the basis for reference values of home BP, that is, the PAMELA (Pressioni Arteriose Monitorate E Loro Associazioni) Study, ${ }^{185,186}$ the Ohasama Study ${ }^{187}$ and the Tecumseh Study. ${ }^{102}$ Thus, reference values of home BP are based on the mean value of the first measurements on each occasion. If the mean of the values on the second or third measurement or the average of multiple measurements on one occasion is used, diagnostic criteria based on new evidence would be necessary.

Despite this fact, the present guidelines permit multiple measurements (1-3 times) of home BP on each occasion. Differences in BP values on a series of multiple measurements indicate the inherent variability of BP, and may include a defense reaction to self-measurement (a kind of white-coat phenomenon). Such variability is con- 
sidered to be a part of the characteristics of BP in that individual. Therefore, as mentioned in Chapter 7, it is desirable to record all values of home $\mathrm{BP}$ on multiple measurements at each point. Although the number of measurements on one occasion recommended by the practitioner to patients and the method to average home BP values (mean of all values, mean of each of the two lower values on each occasion and so on.) may vary, the use of values on the first measurement guarantees a commonality in information and evaluations.

In recent epidemiological studies, the values on two measurements each in the morning and evening for a certain period were averaged. However, these studies also confirmed that means of the values on the first and second measurements reflected target organ damage and prognosis almost comparably. ${ }^{42,128}$ Stergiou et al. ${ }^{177}$ reported that a regression to the mean persistently remains on home BP measurements on each occasion, and home BP on the first measurement must be higher than that on the remaining measurements for that occasion. On the basis of these facts, the present guidelines essentially recommend a single measurement on each occasion, and propose the use of the mean of the values on the single (first) measurement on each occasion for clinical decision making. If multiple measurements are made on each occasion, all values would also be evaluated.

Whether the practitioner pays attention to the lower or higher value, or whether one of the multiple (1-3) measurements is used for a clinical decision, is an issue for the clinical application of home BP allowing practitioners to manage home BP flexibly. Actually, home BP rises or falls on the second or third measurement, but there has been no evidence regarding which home $\mathrm{BP}$ value is optimal for the evaluation of such patients. There is also no evidence concerning a setting for target home BP levels for the control of hypertension in individual patients who show marked variations on repeated measurements. Therefore, antihypertensive treatment must be designed according to the mean of home BP values on the first measurement on each occasion averaged for a certain period. However, we should also pay attention to excessive decreases in BP in patients who show marked decreases on the second and third measurements.

In clinical and epidemiological studies, the decision of the number of measurements on each occasion and the assessment of these values are dependent on the judgment of practitioners and investigators, and home BP values measured under the same conditions should be used for the comparison of epidemiological and clinical data.

The values of how many days (or weeks) should be averaged vary depending on the aim of home BP measurements, but the mean value averaged over 2 or 4 weeks is convenient for daily clinical practice. However, as a method for clinical pharmacology, the mean value averaged over 5 or more days is desirable. ${ }^{56}$ As the day-to-day variability of home BP is also expected to have a prognostic value, ${ }^{51,52}$ it is important to simultaneously calculate the standard deviation of the mean of home BP. Home BP in the morning and evening should be evaluated separately.

\section{CHAPTER 9. DIAGNOSTIC CRITERIA AND TARGET HOME BP LEVELS OF ANTIHYPERTENSIVE TREATMENT}

\section{RECOMMENDATION 8}

Diagnostic criteria and target home BP levels of antihypertensive treatment

1. Diagnostic criteria:

If the mean home BP averaged for a certain period is 135/ $85 \mathrm{~mm} \mathrm{Hg}$, the patient is definitely hypertensive and should be treated. A home BP of $<125 / 80 \mathrm{~mm} \mathrm{Hg}$ is considered normal.
2. Target home BP levels for antihypertensive treatment: The target home BP level of antihypertensive treatment is $<125 / 80 \mathrm{~mm} \mathrm{Hg}$ for young and middle-aged patients, and $<135 / 85 \mathrm{~mm} \mathrm{Hg}$ for elderly people. Target home BP levels of antihypertensive treatment for high-risk patients are $<125 / 75 \mathrm{~mm} \mathrm{Hg}$, but that for patients with cerebrovascular diseases should be $<135 / 85 \mathrm{~mm} \mathrm{Hg}$.

\section{1) DIAGNOSTIC CRITERIA}

Home BP is generally lower than clinic BP. Recently, the diagnosis of hypertension based on home $\mathrm{BP}$ has become more widespread. In the JNC-VI, ${ }^{8} \mathrm{JNC}^{9}$ and ESH-ESC 2003 Guidelines, ${ }^{12}$ a home BP of $135 / 85 \mathrm{~mm} \mathrm{Hg}$ was adopted as a criterion of hypertension on the basis of cross-sectional studies in Western countries and the Ohasama Study in Japan. However, the WHO/ISH Guidelines in $1999^{10}$ considered that a home BP of $125 / 80 \mathrm{~mm} \mathrm{Hg}$ was equivalent to a clinic BP of $140 / 90 \mathrm{~mm} \mathrm{Hg}$, according to the Ohasama Study and so on. Therefore, a home BP $<125 / 80 \mathrm{~mm} \mathrm{Hg}$ was considered normal. In the Ohasama Study, if BPPPP at which the relative risk of death increases by $10 \%$ compared with $\mathrm{BP}$ at which the total mortality rate was lowest was defined as a criterion of hypertension, the value was shown to be $137 / 84 \mathrm{~mm} \mathrm{Hg}{ }^{188}$ On the other hand, as home BP at which the relative risk of cardiovascular death was minimal was 120-127/72$76 \mathrm{~mm} \mathrm{Hg}$, and as the relative risk increased significantly when BP increased to $138 / 83 \mathrm{~mm} \mathrm{Hg}$ in the Ohasama Study, ${ }^{189}$ the JSH $2004^{11}$ proposed a home BP of $135 / 85 \mathrm{~mm} \mathrm{Hg}$ as a criterion of hypertension. This criterion is consistent with that of the international guidelines. The ESH-ESC 2007 guidelines proposed a home BP of 130-135/ $85 \mathrm{~mm} \mathrm{Hg}$ as a criterion of hypertension, revealing a margin of flexibility in SBP. ${ }^{18}$ However, as the criterion proposed by the JSH 2004 has gradually been recognized, ${ }^{21,190}$ the JSH 2009 Guidelines and the present guidelines also indicate $135 / 85 \mathrm{~mm} \mathrm{Hg}$ as a criterion of hypertension (Table 3 ) and $125 / 80 \mathrm{~mm} \mathrm{Hg}$ as a criterion of normotension. Therefore, a value of $125 / 80 \mathrm{~mm} \mathrm{Hg}$ and $<135 / 85 \mathrm{~mm} \mathrm{Hg}$ cannot be regarded as normotension and should be recognized as a high normal range or above.

\section{2) TARGETS OF ANTIHYPERTENSIVE TREATMENT}

Target home BP for antihypertensive treatment differs from the criterion of normal home BP. The results of an interventional study based on home $\mathrm{BP}^{172}$ are expected for the determination of a target home BP, but the JSH Guidelines propose a target home BP for antihypertensive treatment derived from the relationship between home and clinic BPs (Table 4).

In an AHA/ASH/PCNA joint statement, the target of treatment for hypertensive patients in general is a home $\mathrm{BP}$ of $135 / 85 \mathrm{~mm} \mathrm{Hg}$, and

Table 3 Criteria for hypertension in different measurement methods

\begin{tabular}{lcc}
\hline & $\begin{array}{c}\text { Systolic blood } \\
\text { pressure }(\mathrm{mm} \mathrm{Hg})\end{array}$ & $\begin{array}{c}\text { Diastolic blood } \\
\text { pressure (mm Hg) }\end{array}$ \\
\hline Clinic blood pressure & 140 & 90 \\
Home blood pressure & 135 & 85 \\
Ambulatory blood pressure & & \\
24-h & 130 & 80 \\
Day & 135 & 85 \\
Night & 120 & 70 \\
\hline
\end{tabular}

From JSH2009 guidelines. 
Table 4 Expected target blood pressure levels of antihypertensive treatment

\begin{tabular}{lcc}
\hline & $\begin{array}{c}\text { Clinical blood } \\
\text { pressure }\end{array}$ & $\begin{array}{c}\text { Home blood } \\
\text { pressure }\end{array}$ \\
\hline $\begin{array}{l}\text { Young/middle-aged persons } \\
\text { Elderly persons }\end{array}$ & $<130 / 85 \mathrm{~mm} \mathrm{Hg}$ & $<125 / 80 \mathrm{~mm} \mathrm{Hg}$ \\
Diabetics & $<140 / 90 \mathrm{~mm} \mathrm{Hg}$ & $<135 / 85 \mathrm{~mm} \mathrm{Hg}$ \\
Patients with kidney disease & $<130 / 80 \mathrm{~mm} \mathrm{Hg}$ & $<125 / 75 \mathrm{~mm} \mathrm{Hg}$ \\
Patients after myocardial infarction & & \\
Patients with cerebrovascular disorders & $<140 / 90 \mathrm{~mm} \mathrm{Hg}$ & $<135 / 85 \mathrm{~mm} \mathrm{Hg}$ \\
\hline
\end{tabular}

Note: As the criteria for hypertension include a clinic blood pressure of $140 / 90 \mathrm{~mm} \mathrm{Hg}$ and a home blood pressure of $135 / 85 \mathrm{~mm} \mathrm{Hg}$, the differences between clinic blood pressure and home blood pressure $(5 \mathrm{~mm} \mathrm{Hg})$ were simply applied to the clinic blood pressure in each condition and derived provisional target home blood pressure levels.

From JSH2OO9 guidelines.

that for high-risk patients is $130 / 80 \mathrm{~mm} \mathrm{Hg} .{ }^{19}$ Mazze et al. ${ }^{191}$ proposed a home BP of $125 / 75 \mathrm{~mm} \mathrm{Hg}$ as a target of BP control in diabetic patients. According to a meta-analysis of studies on home BP, optimal BP was reported to be $<120 / 80 \mathrm{~mm} \mathrm{Hg} .{ }^{192}$

In the present guidelines, target home BP for antihypertensive treatment for young and middle-aged people is in agreement with the diagnostic criterion for normal BP $(125 / 80 \mathrm{~mm} \mathrm{Hg})$, and that for elderly people and patients with cerebrovascular disorders is in agreement with the diagnostic criterion for hypertension $(135 / 85 \mathrm{~mm} \mathrm{Hg})$. The JSH 2009 Guidelines set the target home BP for antihypertensive treatment at $<125 / 75 \mathrm{~mm} \mathrm{Hg}$ for patients with diabetes, chronic kidney disease (CKD) or those recovering from post-myocardial infarction. In high-risk patients, it is very difficult to reduce home BP to this level, and the J-shaped phenomenon has recently attracted renewed attention. ${ }^{193}$ Although the present guidelines propose $<125 / 75 \mathrm{~mm} \mathrm{Hg}$ as a target of antihypertensive treatment similar to the JSH 2009, milder control of $\mathrm{BP}$ to $<130 / 80 \mathrm{~mm} \mathrm{Hg}$ is considered to be appropriate as a temporal targetttt home BP for hypertensive treatment in these patients. If possible, further reductions in BP (to $<125 / 75 \mathrm{~mm} \mathrm{Hg}$ ) should be attempted depending on the state of theeee disease and safety.

\section{CHAPTER 10. CONCLUSION}

Home BP measurements are important and useful for improvements in the management of hypertension in medical practice, as well as for the recognition of hypertension in the general population. Therefore, the practice of self-BP measurements at home is the first priority, and for this purpose it is not necessarily expected that strict measurement conditions will be set. However, the presence of a standard for home BP measurements may be convenient and useful for practitioners as well as for subjects. The present guidelines for home BP measurements are intended to instruct patients and subjects in the general population on how to measure BP at home. As a result, home BP measurements based on the present guidelines may provide a shared basis of information for clinical decision making.

Fortunately, international reference values are now established. However, the treatment goal for home BP levels has not yet been established. In these guidelines, the normotensive value of home BP is set as $125 / 80 \mathrm{~mm} \mathrm{Hg}$. In the PAMELA study, ${ }^{185,186}$ Ohasama study ${ }^{187}$ and results of the international database, ${ }^{194}$ a home BP of 125/ $80 \mathrm{~mm} \mathrm{Hg}$ is approximately equivalent to a casual-clinic BP level of $140 / 90 \mathrm{~mm} \mathrm{Hg}$. Therefore, it seems that a value of $<125 / 80 \mathrm{~mm} \mathrm{Hg}$ has been suggested as the goal for home BP. However, setting of a goal for home BP must be based on the results of large-scale intervention studies. Among such studies, the Treatment of Hypertension according to the Home or Office Blood Pressure (THOP) study ${ }^{195}$ and the HOMED-BP study ${ }^{172}$ are ongoing. Although such reference values have been proposed in several guidelines, standardization of measurement conditions has not yet been achieved. For example, in the Tecumseh study, the measurement frequency was once in the morning and once in the evening, and the measurement duration was 7 days (14 measurements in total). ${ }^{102}$ In the PAMELA study, ${ }^{185,186}$ home BP was measured once in the morning and once in the evening on only one day (two measurements in total). In the Ohasama study, ${ }^{187}$ home $\mathrm{BP}$ was measured once in the morning and once in the evening for 21 days (42 measurements in total). In these studies, measurement conditions were not strictly set. In the THOP study, home BP was measured three times in the morning and three times in the evening for 7 days, ${ }^{195}$ whereas in the HOMED-BP study, home BP was measured once in the morning and once in the evening for at least 5 days during the run-in period, and an average of these measurements was used as a control value. ${ }^{172}$ Because of the great variety in measurement procedures among studies, it seems impossible to compare results among them. In the future, internationally standardized measurement procedures will be established by consensus, and reference values on the basis of such standardized procedures will be proposed. However, common to all these measurements of home BP values, including those from past databases, is the use of the first measurement on each occasion and the mean of these values for a certain period. Therefore, the common value for home BP, which is available for retrospective analysis, prospective analysis and even for meta-analysis, is the mean of the first measurement on each occasion averaged over a certain period. For this reason, the present guidelines recommend that home BP should be evaluated by the mean of the first measurement in the morning and in the evening, respectively, and these values should be averaged for a certain period.

Standardization of the measurement procedure may elevate the position of home BP measurements in the practice of diagnosing and treating hypertension, and as a result, home BP measurements may bring an improvement in the reliability of screening and diagnosis for hypertension, an improvement in drug adherence and more accurate assessment of BP control during treatment. Home BP measurements under such controlled conditions are expected to have a beneficial effect on the economics of the diagnosis and management of hypertension.

\section{CONFLICT OF INTEREST}

The authors declare no conflict of interest.

1 Riva-Rocci S. Un nuovo sfigmomanometro. Gaz Med Torino 1896; 47: 981-996.

2 Korotkoff NS. On the subject of methods of measuring blood pressure. Bull Imp Military Med Scad (St Petersburg) 1905; 11: 365-367.

3 Posey JA, Geddes LA, Williams H, Moore AG. The meaning of the point of maximum oscillations in cuff pressure in the indirect measurement of blood pressure. 1. Cardiovasc Res Cent Bull 1969; 8: 15-25.

4 Ayman D, Goldshine AD. Blood pressure determination by patients with essential hypertension. 1 . The difference between clinic and home readings before treatment. Am J Med Sci 1940; 200: 465-474.

5 Bevan AT, Honour AJ, Stott FH. Direct arterial pressure recording in unrestricted man. Clin Sci 1969; 36: 329-344.

6 Shirasaki O, Terada H, Niwano K, Nakanishi T, Kanai M, Miyawaki Y, Souma T, Tanaka T, Kusunoki T. The Japan Home-health Apparatus Industrial Association: Investigation of home-use electronic sphygmomanometers. Blood Press Monit 2001; 6: 303-307.

7 Chonan K, Kikuya M, Araki T, Fujiwara T, Suzuki M, Michimata M, Hashimoto J, Ohkubo T, Hozawa A, Yamamoto N, Miyawaki Y, Matsubara M, Imai Y. Device for the 
self-measurement of blood pressure that can monitor blood pressure during sleep. Blood Press Monit 2001; 6: 203-205.

8 The sixth report of the Joint National Committee on prevention, detection, evaluation, and treatment of high blood pressure. Arch Intern Med 1997; 157: 2413-2446.

9 Chobanian AV, Bakris GL, Black HR, Cushman WC, Green LA, Izzo Jr JL, Jones DW, Materson BJ, Oparil S, Wright Jr JT, Roccella EJ. The Seventh Report of the Joint National Committee on prevention, detection, evaluation, and treatment of high blood pressure: The JNC 7 report. JAMA 2003; 289: 2560-2572.

10 Guidelines Subcommittee. 1999 World Health Organization-International Society of Hypertension Guidelines for the management of hypertension. J Hypertens 1999; 17: 151-183.

11 Japanese Society of Hypertension Guidelines for the management of hypertension (JSH 2004). Hypertens Res 2006; 29(Suppl): S1-S105.

12 European Society of Hypertension-European Society of Cardiology Guidelines Committee. 2003 European Society of Hypertension-European Society of Cardiology guidelines for the management of arterial hypertension. J Hypertens 2003; 21 : 1011-1053.

13 Imai Y, Otsuka K, Kawano Y, Shimada K, Hayashi H, Tochikubo O, Miyakawa M, Fukiyama K. Japanese Society of Hypertension. Japanese Society of Hypertension (JSH) guidelines for self-monitoring of blood pressure at home. Hypertens Res 2003; 26: 771-782.

14 Pickering TG, Hall JE, Appel LJ, Falkner BE, Graves J, Hill MN, Jones DW, Kurtz T, Sheps SG, Roccella EJ. Recommendations for blood pressure measurement in humans and experimental animals: Part 1: Blood pressure measurement in humans: a statement for professionals from the Subcommittee of Professional and Public Education of the American Heart Association Council on High Blood Pressure Research. Hypertension 2005; 45: 142-161.

15 O'Brien E, Asmar R, Beilin L, Imai Y, Mancia G, Mengden T, Myers M, Padfield P, Palatini P, Parati G, Pickering T, Redon J, Staessen J, Stergiou G, Verdecchia P. Practice guidelines of the European Society of Hypertension for clinic, ambulatory and self blood pressure measurement. J Hypertens 2005; 23: 697-701.

16 Canadian Hypertension Education Program. The 2007 Canadian Hypertension Education Program recommendations: the scientific summary-an annual update. Can J Cardiol 2007; 23: 521-527.

17 Parati G, Stergiou GS, Asmar R, Bilo G, de Leeuw P, Imai Y, Kario K, Lurbe E, Manolis A, Mengden T, O'Brien E, Ohkubo T, Padfield P, Palatini P, Pickering T, Redon J, Revera M, Ruilope LM, Shennan A, Staessen JA, Tisler A, Waeber B, Zanchetti A, Mancia G. European Society of Hypertension guidelines for blood pressure monitoring at home: a summary report of the Second International Consensus Conference on Home Blood Pressure Monitoring. J Hypertens 2008; 26: 1505-1526.

18 Mancia G, De Backer G, Dominiczak A, Cifkova R, Fagard R, Germano G, Grassi G, Heagerty AM, Kjeldsen SE, Laurent S, Narkiewicz K, Ruilope L, Rynkiewicz A, Schmieder RE, Boudier HA, Zanchetti A, Vahanian A, Camm J, De Caterina R, Dean V, Dickstein K, Filippatos G, Funck-Brentano C, Hellemans I, Kristensen SD, McGregor K, Sechtem U, Silber S, Tendera M, Widimsky P, Zamorano JL, Erdine S, Kiowski W, Agabiti-Rosei E, Ambrosioni E, Lindholm LH, Viigimaa M, Adamopoulos S, Bertomeu V, Clement D, Farsang C, Gaita D, Lip G, Mallion JM, Manolis AJ, Nilsson PM, O'Brien E, Ponikowski P, Redon J, Ruschitzka F, Tamargo J, van Zwieten P, Waeber B, Williams B. Management of Arterial Hypertension of the European Society of Hypertension; European Society of Cardiology. 2007 Guidelines for the Management of Arterial Hypertension: The Task Force for the Management of Arterial Hypertension of the European Society of Hypertension (ESH) and of the European Society of Cardiology (ESC). J Hypertens 2007; 25: 1105-1187.

19 Pickering TG, Miller NH, Ogedegbe G, Krakoff LR, Artinian NT, Goff D. Call to action on use and reimbursement for home blood pressure monitoring: a joint scientific statement from the American Heart Association, American Society of Hypertension, and Preventive Cardiovascular Nurses Association. Hypertension 2008; 52: 10-29.

20 Ogihara T, Kikuchi K, Matsuoka H, Fujita T, Higaki J, Horiuchi M, Imai Y, Imaizumi T, Ito $S$, Iwao $H$, Kario K, Kawano $Y$, Kim-Mitsuyama S, Kimura G, Matsubara $H$, Matsuura H, Naruse M, Saito I, Shimada K, Shimamoto K, Suzuki H, Takishita S, Tanahashi N, Tsuchihashi T, Uchiyama M, Ueda S, Ueshima H, Umemura S, Ishimitsu $\mathrm{T}$, Rakugi $\mathrm{H}$. The Japanese Society of Hypertension Guidelines for the Management of Hypertension (JSH 2009). Hypertens Res 2009; 32: 3-107.

21 Obara T, Ohkubo T, Fukunaga H, Kobayashi M, Satoh M, Metoki H, Asayama K, Inoue R, Kikuya M, Mano N, Miyakawa M, Imai Y. Practice and awareness of physicians regarding home blood pressure measurement in Japan. Hypertens Res 2010; 33 . 428-434.

22 Sakuma M, Imai Y, Nagai K, Watanabe N, Sakuma H, Minami N, Satoh H, Abe K. Reproducibility of home blood pressure measurements over a 1-year period. Am J Hypertens 1997; 10: 798-803.

23 Brueren MM, van Limpt P, Schouten HJ, de Leeuw PW, van Ree JW. Is a series of blood pressure measurements by the general practitioner or the patient a reliable alternative to ambulatory blood pressure measurement? A study in general practice with reference to short-term and long-term between-visit variability. Am J Hypertens 1997; 10: 879-885.

24 Stergiou GS, Baibas NM, Gantzarou AP, Skeva II, Kalkana CB, Roussias LG, Mountokalakis TD. Reproducibility of home, ambulatory, and clinic blood pressure: implications for the design of trials for the assessment of antihypertensive drug efficacy. Am J Hypertens 2002; 15: 101-104.

25 Hernandez-del Rey R, Martin-Baranera M, Sobrino J, Gorostidi M, Vinyoles E, Sierra C, Segura J, Coca A, Ruilope LM. Reproducibility of the circadian blood pressure pattern in 24-h versus 48-h recordings: The Spanish Ambulatory Blood Pressure Monitoring Registry. J Hypertens 2007; 25: 2406-2412.
26 Cuspidi C, Meani S, Salerno M, Valerio C, Fusi V, Severgnini B, Lonati L, Magrini F, Zanchetti A. Cardiovascular target organ damage in essential hypertensives with or without reproducible nocturnal fall in blood pressure. J Hypertens 2004; 22: 273-280.

27 White WB, Larocca GM. Improving the utility of the nocturnal hypertension definition by using absolute sleep blood pressure rather than the "dipping" proportion. $\mathrm{Am} \mathrm{J}$ Cardiol 2003; 92: 1439-1441.

28 Manning G, Rushton L, Donnelly R, Millar-Craig MW. Variability of diurnal changes in ambulatory blood pressure and nocturnal dipping status in untreated hypertensive and normotensive subjects. Am J Hypertens 2000; 13: 1035-1038.

29 Mochizuki Y, Okutani M, Donfeng Y, Iwasaki H, Takusagawa M, Kohno I, Mochizuki S, Umetani K, Ishii H, Ijiri H, Komori S, Tamura K. Limited reproducibility of circadian variation in blood pressure dippers and nondippers. Am J Hypertens 1998; 11: 403-409.

30 Imai Y, Ohkubo T, Kikuya M, Hashimoto J. Practical aspect of monitoring hypertension based on self-measured blood pressure at home. Intern Med 2004; 43: 771-778.

31 Fagard RH, Van Den Broeke C, De Cort P. Prognostic significance of blood pressure measured in the office, at home and during ambulatory monitoring in older patients in general practice. J Hum Hypertens 2005; 19: 801-807.

32 Sega R, Facchetti R, Bombelli M, Cesana G, Corrao G, Grassi G, Mancia G. Prognostic value of ambulatory and home blood pressures compared with office blood pressure in the general population: follow-up results from the Pressioni Arteriose Monitorate $E$ Loro Associazioni (PAMELA) study. Circulation 2005; 111: 1777-1783.

33 Mancia G, Facchetti R, Bombelli M, Grassi G, Sega R. Long-term risk of mortality associated with selective and combined elevation in office, home, and ambulatory blood pressure. Hypertension 2006; 47: 846-853.

34 Ohkubo T, Imai Y, Tsuji I, Nagai K, Kato J, Kikuchi N, Nishiyama A, Aihara A, Sekino M, Kikuya M, Ito S, Satoh H, Hisamichi S. Home blood pressure measurement has a stronger predictive power for mortality than does screening blood pressure measurement: a population-based observation in Ohasama, Japan. J Hypertens 1998; 16: 971-975.

35 Ohkubo T, Asayama K, Kikuya M, Metoki H, Hoshi H, Hashimoto J, Totsune K, Satoh $\mathrm{H}$, Imai Y. Ohasama study. How many times should blood pressure be measured at home for better prediction of stroke risk? Ten-year follow-up results from the Ohasama study. J Hypertens 2004; 22: 1099-1104.

36 Asayama K, Ohkubo T, Kikuya M, Metoki H, Hoshi H, Hashimoto J, Totsune K, Satoh $\mathrm{H}$, Imai Y. Prediction of stroke by self-measurement of blood pressure at home versus casual screening blood pressure measurement in relation to the Joint National Committee 7 classification: The Ohasama study. Stroke 2004; 35: 2356-2361.

37 Hozawa A, Ohkubo T, Nagai K, Kikuya M, Matsubara M, Tsuji I, Ito S, Satoh H, Hisamichi S, Imai Y. Prognosis of isolated systolic and isolated diastolic hypertension as assessed by self-measurement of blood pressure at home: The Ohasama study. Arch Intern Med 2000; 160: 3301-3306.

38 Asayama K, Ohkubo T, Kikuya M, Metoki H, Obara T, Hoshi H, Hashimoto J, Totsune K, Satoh H, Imai Y. Use of 2003 European Society of Hypertension-European Society of Cardiology guidelines for predicting stroke using self-measured blood pressure at home: The Ohasama study. Eur Heart J 2005; 26: 2026-2031.

39 Niiranen TJ, Hanninen MR, Johansson J, Reunanen A, Jula AM. Home-measured blood pressure is a stronger predictor of cardiovascular risk than office blood pressure: The finn-home study. Hypertension 2010; 55: 1346-1351.

40 Yasui D, Asayama K, Ohkubo T, Kikuya M, Kanno A, Hara A, Hirose T, Obara T, Metoki $\mathrm{H}$, Inoue R, Totsune K, Hoshi H, Satoh H, Imai Y. Stroke risk in treated hypertension based on home blood pressure: The Ohasama study. Am J Hypertens 2010; 23: 508-514.

41 Bobrie G, Chatellier G, Genes N, Clerson P, Vaur L, Vaisse B, Menard J, Mallion JM. Cardiovascular prognosis of "masked hypertension" detected by blood pressure selfmeasurement in elderly treated hypertensive patients. JAMA 2004; 291: 1342-1349.

42 Johansson JK, Niiranen TJ, Puukka PJ, Jula AM. Optimal schedule for home blood pressure monitoring based on a clinical approach. J Hypertens 2010; 28: 259-264.

43 Gaborieau V, Delarche N, Gosse P. Ambulatory blood pressure monitoring versus selfmeasurement of blood pressure at home: Correlation with target organ damage. J Hypertens 2008; 26: 1919-1927.

44 Stergiou GS, Argyraki KK, Moyssakis I, Mastorantonakis SE, Achimastos AD, Karamanos VG, Roussias LG. Home blood pressure is as reliable as ambulatory blood pressure in predicting target-organ damage in hypertension. Am J Hypertens 2007; 20: 616-621.

45 Shimbo D, Pickering TG, Spruill TM, Abraham D, Schwartz JE, Gerin W. Relative utility of home, ambulatory, and office blood pressures in the prediction of end-organ damage. Am J Hypertens 2007; 20: 476-482.

46 Mancia G, Zanchetti A, Agabiti-Rosei E, Benemio G, De Cesaris R, Fogari R, Pessina A, Porcellati C, Rappelli A, Salvetti A, Trimarco B. Ambulatory blood pressure is superior to clinic blood pressure in predicting treatment-induced regression of left ventricular hypertrophy. Sample study group. Study on ambulatory monitoring of blood pressure and lisinopril evaluation. Circulation 1997; 95: 1464-1470.

47 Leary AC, Donnan PT, MacDonald TM, Murphy MB. The white-coat effect is associated with increased blood pressure reactivity to physical activity. Blood Press Monit 2002; 7: 209-213.

48 Kikuya M, Hozawa A, Ohokubo T, Tsuji I, Michimata M, Matsubara M, Ota M, Nagai K, Araki T, Satoh H, Ito S, Hisamichi S, Imai Y. Prognostic significance of blood pressure and heart rate variabilities: The Ohasama study. Hypertension 2000; 36: 901-906.

49 Verdecchia P, Angeli F, Gattobigio R, Rapicetta C, Reboldi G. Impact of blood pressure variability on cardiac and cerebrovascular complications in hypertension. $\mathrm{Am} \mathrm{J}$ Hypertens 2007; 20: 154-161. 
50 Eguchi K, Ishikawa J, Hoshide S, Pickering TG, Schwartz JE, Shimada K, Kario K. Night time blood pressure variability is a strong predictor for cardiovascular events in patients with type 2 diabetes. Am J Hypertens 2009; 22: 46-51.

51 Kikuya M, Ohkubo T, Metoki H, Asayama K, Hara A, Obara T, Inoue R, Hoshi H, Hashimoto J, Totsune K, Satoh H, Imai Y. Day-by-day variability of blood pressure and heart rate at home as a novel predictor of prognosis: The Ohasama study. Hypertension 2008; 52: 1045-1050.

52 Parati G, Bilo G. Clinical relevance of day-by-day blood pressure and heart rate variability: New information from home self-measurements. Hypertension 2008; 52 : 1006-1008.

53 Hozawa A, Ohkubo T, Kikuya M, Ugajin T, Yamaguchi J, Asayama K, Metoki H, Ohmori K, Hoshi H, Hashimoto J, Satoh H, Tsuji I, Imai Y. Prognostic value of home heart rate for cardiovascular mortality in the general population: The Ohasama study. Am J Hypertens 2004; 17: 1005-1010.

54 Vaur L, Dubroca II, Dutrey-Dupagne C, Genes N, Chatellier G, Bouvier-d'Yvoire M, Elkik F, Menard J. Superiority of home blood pressure measurements over office measurements for testing antihypertensive drugs. Blood Press Monit 1998; 3: 107-114.

55 Ragot S, Genes N, Vaur L, Herpin D. Comparison of three blood pressure measurement methods for the evaluation of two antihypertensive drugs: Feasibility, agreement, and reproducibility of blood pressure response. Am J Hypertens 2000; 13: 632-639.

56 Imai Y, Ohkubo T, Hozawa A, Tsuji I, Matsubara M, Araki T, Chonan K, Kikuya M, Satoh $\mathrm{H}$, Hisamichi S, Nagai K. Usefulness of home blood pressure measurements in assessing the effect of treatment in a single-blind placebo-controlled open trial. $J$ Hypertens 2001; 19: 179-185.

57 Menard J, Chatellier G, Day M, Vaur L. Self-measurement of blood pressure at home to evaluate drug effects by the trough: Peak ratio. J Hypertens Supp/ 1994; 12: S21-S25.

58 Stergiou GS, Efstathiou SP, Skeva II, Baibas NM, Roussias LG, Mountokalakis TD. Comparison of the smoothness index, the trough : Peak ratio and the morning : Evening ratio in assessing the features of the antihypertensive drug effect. $J$ Hypertens 2003; 21: 913-920.

59 Omboni S, Fogari R, Palatini P, Rappelli A, Mancia G. Reproducibility and clinical value of the trough-to-peak ratio of the antihypertensive effect: Evidence from the sample study. Hypertension 1998; 32: 424-429.

60 Hashimoto J, Chonan K, Aoki Y, Ugajin T, Yamaguchi J, Nishimura T, Kikuya M, Michimata M, Matsubara M, Araki T, Hozawa A, Ohkubo T, Imai Y. Therapeutic effects of evening administration of guanabenz and clonidine on morning hypertension: Evaluation using home-based blood pressure measurements. J Hypertens 2003; 21: 805-811.

61 Rogers MA, Small D, Buchan DA, Butch CA, Stewart CM, Krenzer BE, Husovsky HL. Home monitoring service improves mean arterial pressure in patients with essential hypertension. A randomized, controlled trial. Ann Intern Med 2001; 134: 1024-1032.

62 Moller DS, Dideriksen A, Sorensen S, Madsen LD, Pedersen EB. Accuracy of telemedical home blood pressure measurement in the diagnosis of hypertension. J Hum Hypertens 2003; 17: 549-554.

63 Rudd P, Miller NH, Kaufman J, Kraemer HC, Bandura A, Greenwald G, Debusk RF. Nurse management for hypertension. A systems approach. Am J Hypertens 2004; 17: 921-927.

64 Logan AG, Mclsaac WJ, Tisler A, Irvine MJ, Saunders A, Dunai A, Rizo CA, Feig DS, Hamill M, Trudel M, Cafazzo JA. Mobile phone-based remote patient monitoring system for management of hypertension in diabetic patients. Am J Hypertens 2007; 20: 942-948.

65 Parati G, Pickering TG. Home blood-pressure monitoring: US and European consensus. Lancet 2009; 373: 876-878.

66 Nakamoto H, Nishida E, Ryuzaki M, Sone M, Suzuki H, Yoshimoto M, Itagaki K. Effect of telmisartan and amlodipine on home blood pressure by monitoring newly developed telemedicine system: Monitoring test by using telemedicine. Telmisartan's effect on home blood pressure (TelTelbosu). Clin Exp Hypertens 2008; 30: 57-67.

67 Verberk WJ, Kroon AA, Lenders JW, Kessels AG, van Montfrans GA, Smit AJ, van der Kuy PH, Nelemans PJ, Rennenberg RJ, Grobbee DE, Beltman FW, Joore MA, Brunenberg DE, Dirksen C, Thien T, de Leeuw PW. Self-measurement of blood pressure at home reduces the need for antihypertensive drugs: a randomized, controlled trial. Hypertension 2007; 50: 1019-1025.

68 Ryuzaki M, Nakamoto H, Nishida E, Sone M, Nakajima S, Yoshimoto M, Suzuki Y, Itagaki K. Crossover study of amlodipine versus nifedipine $\mathrm{cr}$ with home blood pressure monitoring via cellular phone: Internet-mediated open-label crossover trial of calcium channel blockers for hypertension (i-TECHO trial). J Hypertens 2007; 25: 2352-2358.

69 Green BB, Cook AJ, Ralston JD, Fishman PA, Catz SL, Carlson J, Carrell D, Tyll L, Larson EB, Thompson RS. Effectiveness of home blood pressure monitoring, web communication, and pharmacist care on hypertension control: a randomized controlled trial. JAMA 2008; 299: 2857-2867.

70 Parati G, Omboni S, Albini F, Piantoni L, Giuliano A, Revera M, Illyes M, Mancia G. Home blood pressure telemonitoring improves hypertension control in general practice. The TeleBPCare study. J Hypertens 2009; 27: 198-203.

71 McManus RJ, Mant J, Bray EP, Holder R, Jones MI, Greenfield S, Kaambwa B, Banting M, Bryan S, Little P, Williams B, Hobbs FD. Telemonitoring and self-management in the control of hypertension (TASMINH2): a randomised controlled trial. Lancet 2010; 376: $163-172$.
72 Halme L, Vesalainen R, Kaaja M, Kantola I. Self-monitoring of blood pressure promotes achievement of blood pressure target in primary health care. Am J Hypertens 2005; 18: 1415-1420.

73 Cappuccio FP, Kerry SM, Forbes L, Donald A. Blood pressure control by home monitoring: meta-analysis of randomised trials. BMJ 2004; 329: 145

74 Zarnke KB, Feagan BG, Mahon JL, Feldman RD. A randomized study comparing a patient-directed hypertension management strategy with usual office-based care. Am J Hypertens 1997; 10: 58-67.

75 Canzanello VJ, Jensen PL, Hunder I. Rapid adjustment of antihypertensive drugs produces a durable improvement in blood pressure. Am J Hypertens 2001; 14: 345-350.

76 Cuspidi C, Meani S, Fusi V, Salerno M, Valerio C, Severgnini B, Catini E, Leonetti G, Magrini F, Zanchetti A. Home blood pressure measurement and its relationship with blood pressure control in a large selected hypertensive population. J Hum Hypertens 2004; 18: 725-731.

77 Staessen JA, Den Hond E, Celis H, Fagard R, Keary L, Vandenhoven G, O'Brien ET. Antihypertensive treatment based on blood pressure measurement at home or in the physician's office: a randomized controlled trial. JAMA 2004; 291: 955-964.

78 Bosworth HB, Olsen MK, Grubber JM, Neary AM, Orr MM, Powers BJ, Adams MB, Svetkey LP, Reed SD, Li Y, Dolor RJ, Oddone EZ. Two self-management interventions to improve hypertension control: a randomized trial. Ann Intern Med 2009; 151: 687-695.

79 Hozawa A, Shimazu T, Kuriyama S, Tsuji I. Benefit of home blood pressure measurement after a finding of high blood pressure at a community screening. $J$ Hypertens 2006; 24: 1265-1271.

80 Ashida T, Yokoyama S, Ebihara A, Sugiyama T, Fujii J. Profiles of patients who control the doses of their antihypertensive drugs by self-monitoring of home blood pressure. Hypertens Res 2001; 24: 203-207.

81 Bobrie G, Postel-Vinay N, Delonca J, Corvol P. SETHI Investigators. Self-measurement and self-titration in hypertension: A pilot telemedicine study. Am J Hypertens 2007; 20: 1314-1320.

82 Ogedegbe G, Schoenthaler A. A systematic review of the effects of home blood pressure monitoring on medication adherence. J Clin Hypertens (Greenwich) 2006; 8: $174-180$.

83 van Onzenoort HA, Verberk WJ, Kroon AA, Kessels AG, Nelemans PJ, van der Kuy PH, Neef $C$, de Leeuw PW. Effect of self-measurement of blood pressure on adherence to treatment in patients with mild-to-moderate hypertension. J Hypertens 2010; 28 : $622-627$

84 Kim J, Han HR, Song H, Lee J, Kim KB, Kim MT. Compliance with home blood pressure monitoring among middle-aged korean americans with hypertension. J Clin Hypertens (Greenwich). 2010; 12: 253-260.

85 Saito I, Nomura M, Hirose H, Kawabe H. Use of home blood pressure monitoring and exercise, diet and medication compliance in Japan. Clin Exp Hypertens 2010; 32: 210-213.

86 Imai Y, Munakata M, Tsuji I, Ohkubo T, Satoh H, Yoshino H, Watanabe N, Nishiyama A, Onodera N, Kato J, Sekino M, Aihara A, Kasai Y, Abe K. Seasonal variation in blood pressure in normotensive women studied by home measurements. Clin Sci (Lond) 1996; 90: 55-60.

87 Minami J, Ishimitsu T, Kawano Y, Matsuoka H. Seasonal variations in office and home blood pressures in hypertensive patients treated with antihypertensive drugs. Blood Press Monit 1998; 3: 101-106.

88 Rave K, Bender R, Heise T, Sawicki PT. Value of blood pressure self-monitoring as a predictor of progression of diabetic nephropathy. J Hypertens 1999; 17: 597-601.

89 Iwabu A, Konishi K, Tokutake H, Yamane S, Ohnishi H, Tominaga Y, Kusachi S. Inverse correlation between seasonal changes in home blood pressure and atmospheric temperature in treated-hypertensive patients. Clin Exp Hypertens 2010; 32: 221-226.

90 Kimura T, Senda S, Masugata H, Yamagami A, Okuyama H, Kohno T, Hirao T, Fukunaga M, Okada H, Goda F. Seasonal blood pressure variation and its relationship to environmental temperature in healthy elderly Japanese studied by home measurements. Clin Exp Hypertens 2010; 32: 8-12.

91 Metoki H, Ohkubo T, Watanabe Y, Nishimura M, Sato Y, Kawaguchi M, Hara A, Hirose T, Obara T, Asayama K, Kikuya M, Yagihashi K, Matsubara Y, Okamura K, Mori S, Suzuki M, Imai Y. Seasonal trends of blood pressure during pregnancy in Japan: the babies and their parents' longitudinal observation in Suzuki Memorial Hospital in Intrauterine Period study. J Hypertens 2008; 26: 2406-2413.

92 Tsubota-Utsugi M, Ohkubo T, Kikuya M, Metoki H, Kurimoto A, Suzuki K, Fukushima $\mathrm{N}$, Hara A, Asayama $\mathrm{K}$, Satoh $\mathrm{H}$, Tsubono $\mathrm{Y}$, Imai $\mathrm{Y}$. High fruit intake is associated with a lower risk of future hypertension determined by home blood pressure measurement: the Ohasama study. J Hum Hypertens 2011; 25: 164-171.

93 Ohkubo T, Hozawa A, Nagatomi R, Fujita K, Sauvaget C, Watanabe Y, Anzai Y, Tamagawa A, Tsuji I, Imai Y, Ohmori H, Hisamichi S. Effects of exercise training on home blood pressure values in older adults: a randomized controlled trial. $J$ Hypertens 2001; 19: 1045-1052.

94 Seki M, Inoue R, Ohkubo T, Kikuya M, Hara A, Metoki H, Hirose T, Tsubota-Utsugi M, Asayama K, Kanno A, Obara T, Hoshi H, Totsune K, Satoh H, Imai Y. Association of environmental tobacco smoke exposure with elevated home blood pressure in Japanese women: the Ohasama study. J Hypertens 2010; 28: 1814-1820.

95 Watanabe Y, Metoki H, Ohkubo T, Hirose T, Kikuya M, Asayama K, Inoue R, Hara A, Obara T, Hoshi H, Totsune K, Imai Y. Parental longevity and offspring's home blood pressure: the Ohasama study. J Hypertens 2010; 28: 272-277. 
96 Watanabe Y, Metoki H, Ohkubo T, Katsuya T, Tabara Y, Kikuya M, Hirose T, Sugimoto K, Asayama K, Inoue R, Hara A, Obara T, Nakura J, Kohara K, Totsune K, Ogihara T, Rakugi H, Miki T, Imai Y. Accumulation of common polymorphisms is associated with development of hypertension: A 12-year follow-up from the Ohasama study. Hypertens Res 2010; 33: 129-134.

97 Kawano Y, Yoshimi H, Matsuoka H, Takishita S, Omae T. Calcium supplementation in patients with essential hypertension: assessment by office, home and ambulatory blood pressure. J Hypertens 1998; 16: 1693-1699.

98 Kawano Y, Pontes CS, Abe H, Takishita S, Omae T. Effects of alcohol consumption and restriction on home blood pressure in hypertensive patients: serial changes in the morning and evening records. Clin Exp Hypertens 2002; 24: 33-39.

99 Padmanabhan S, Menni C, Lee WK, Laing S, Brambilla P, Sega R, Perego R, Grassi G, Cesana G, Delles C, Mancia G, Dominiczak AF. The effects of sex and method of blood pressure measurement on genetic associations with blood pressure in the PAMELA study. J Hypertens 2010; 28: 465-477.

100 Ugajin T, Hozawa A, Ohkubo T, Asayama K, Kikuya M, Obara T, Metoki H, Hoshi H, Hashimoto J, Totsune K, Satoh H, Tsuji I, Imai Y. White-coat hypertension as a risk factor for the development of home hypertension: the ohasama study. Arch Intern Med 2005; 165: 1541-1546.

101 Mancia G, Bombelli M, Facchetti R, Madotto F, Quarti-Trevano F, Polo Friz H, Grassi G, Sega R. Long-term risk of sustained hypertension in white-coat or masked hypertension. Hypertension 2009; 54: 226-232.

102 Julius S, Mejia A, Jones K, Krause L, Schork N, van de Ven C, Johnson E, Petrin J, Sekkarie MA, Kjeldsen SE, Schmouder R, Gupta R, Ferraro J, Nazzaro P, Weissfeld J. "White coat versus" "sustained" borderline hypertension in Tecumseh, Michigan. Hypertension 1990; 16: 617-623.

103 Sega R, Trocino G, Lanzarotti A, Carugo S, Cesana G, Schiavina R, Valagussa F, Bombelli M, Giannattasio C, Zanchetti A, Mancia G. Alterations of cardiac structure in patients with isolated office, ambulatory, or home hypertension: data from the general population (Pressione Arteriose Monitorate E Loro Associazioni [PAMELA] Study). Circulation 2001; 104: 1385-1392.

104 Hozawa A, Ohkubo T, Kikuya M, Yamaguchi J, Ohmori K, Fujiwara T, Hashimoto J, Matsubar M, Kitaoka H, Nagai K, Tsuji I, Satoh H, Hisamichi S, Imai Y. Blood pressure control assessed by home, ambulatory and conventional blood pressure measurements in the Japanese general population: the Ohasama study. Hypertens Res 2002; 25 : 57-63.

105 Niiranen TJ, Jula AM, Kantola IM, Reunanen A. Prevalence and determinants of isolated clinic hypertension in the finnish population: the Finn-HOME study. $J$ Hypertens 2006; 24: 463-470.

106 Shimada K, Fujita T, Ito S, Naritomi H, Ogihara T, Shimamoto K, Tanaka H, Yoshiike $\mathrm{N}$. The importance of home blood pressure measurement for preventing stroke and cardiovascular disease in hypertensive patients: a sub-analysis of the Japan Hypertension Evaluation with Angiotensin II Antagonist Losartan Therapy (J-HEALTH) study, a prospective nationwide observational study. Hypertens Res 2008; 31: 1903-1911.

107 Obara T, Ohkubo T, Kikuya M, Asayama K, Metoki H, Inoue R, Oikawa T, Komai R, Murai K, Horikawa T, Hashimoto J, Totsune K, Imai Y. Prevalence of masked uncontrolled and treated white-coat hypertension defined according to the average of morning and evening home blood pressure value: from the Japan Home versus Office Measurement Evaluation Study. Blood Press Monit 2005; 10: 311-316.

108 Bobrie G, Genes N, Vaur L, Clerson P, Vaisse B, Mallion JM, Chatellier G. Is "isolated home" hypertension as opposed to "isolated office" hypertension a sign of greater cardiovascular risk? Arch Intern Med 2001; 161: 2205-2211.

109 Ohkubo T, Imai Y, Tsuji I, Nagai K, Watanabe N, Minami N, Kato J, Kikuchi N, Nishiyama A, Aihara A, Sekino M, Satoh H, Hisamichi S. Relation between nocturnal decline in blood pressure and mortality. The Ohasama study. Am J Hypertens 1997; 10: 1201-1207.

110 Kario K, Pickering TG, Umeda Y, Hoshide S, Hoshide Y, Morinari M, Murata M, Kuroda T, Schwartz JE, Shimada K. Morning surge in blood pressure as a predictor of silent and clinical cerebrovascular disease in elderly hypertensives: a prospective study. Circulation 2003; 107: 1401-1406.

111 Chonan K, Hashimoto J, Ohkubo T, Tsuji I, Nagai K, Kikuya M, Hozawa A, Matsubara M, Suzuki M, Fujiwara T, Araki T, Satoh H, Hisamichi S, Imai Y. Insufficient duration of action of antihypertensive drugs mediates high blood pressure in the morning in hypertensive population: the Ohasama study. Clin Exp Hypertens 2002; 24: 261-275.

112 Ohkubo T, Kikuya M, Metoki H, Asayama K, Obara T, Hashimoto J, Totsune K, Hoshi $\mathrm{H}$, Satoh H, Imai Y. Prognosis of "masked" hypertension and "white-coat" hypertension detected by 24-h ambulatory blood pressure monitoring 10-year follow-up from the Ohasama study. J Am Coll Cardiol 2005; 46: 508-515.

113 Obara T, Ohkubo T, Funahashi J, Kikuya M, Asayama K, Metoki H, Oikawa T, Hashimoto J, Totsune K, Imai Y. Isolated uncontrolled hypertension at home and in the office among treated hypertensive patients from the J-HOME study. J Hypertens 2005; 23: 1653-1660.

114 Kawabe H, Saito I, Saruta T. Status of home blood pressure measured in morning and evening: evaluation in normotensives and hypertensives in Japanese urban population. Hypertens Res 2005; 28: 491-498.

115 Metoki H, Ohkubo T, Kikuya M, Asayama K, Obara T, Hashimoto J, Totsune K, Hoshi $\mathrm{H}$, Satoh H, Imai Y. Prognostic significance for stroke of a morning pressor surge and a nocturnal blood pressure decline: the Ohasama study. Hypertension 2006; 47 149-154.

116 Kamoi K, Miyakoshi M, Soda S, Kaneko S, Nakagawa O. Usefulness of home blood pressure measurement in the morning in type 2 diabetic patients. Diabetes Care 2002; 25: 2218-2223.
117 Asayama K, Ohkubo T, Kikuya M, Obara T, Metoki H, Inoue R, Hara A, Hirose T, Hoshi $\mathrm{H}$, Hashimoto J, Totsune K, Satoh H, Imai Y. Prediction of stroke by home "morning" versus "evening" blood pressure values: the Ohasama study. Hypertension 2006; 48 : 737-743.

118 Kario K, Ishikawa J, Pickering TG, Hoshide S, Eguchi K, Morinari M, Hoshide Y, Kuroda T, Shimada K. Morning hypertension: the strongest independent risk factor for stroke in elderly hypertensive patients. Hypertens Res 2006; 29: 581-587.

119 Imai Y, Nishiyama A, Sekino M, Aihara A, Kikuya M, Ohkubo T, Matsubara M, Hozawa A, Tsuji I, Ito S, Satoh H, Nagai K, Hisamichi S. Characteristics of blood pressure measured at home in the morning and in the evening: the Ohasama study. $J$ Hypertens 1999; 17: 889-898.

120 Kawabe H, Saito I. Determinants of exaggerated difference in morning and evening home blood pressure in Japanese normotensives. Hypertens Res 2009; 32: 1028-1031.

121 Obara T, Ito K, Ohkubo T, Shibamiya T, Shinki T, Nakashita M, Hara A, Metoki H, Inoue R, Asayama K, Kikuya M, Mano N, Imai Y. Uncontrolled hypertension based on morning and evening home blood pressure measurements from the J-HOME study. Hypertens Res 2009; 32: 1072-1078.

122 Ishikawa J, Kario K, Hoshide S, Eguchi K, Morinari M, Kaneda R, Umeda Y, Ishikawa S, Kuroda T, Hojo Y, Shimada K. Determinants of exaggerated difference in morning and evening blood pressure measured by self-measured blood pressure monitoring in medicated hypertensive patients: Jichi Morning Hypertension Research (J-MORE) Study. Am J Hypertens 2005; 18: 958-965.

123 Matsui Y, Eguchi K, Shibasaki S, Shimizu M, Ishikawa J, Shimada K, Kario K. Association between the morning-evening difference in home blood pressure and cardiac damage in untreated hypertensive patients. J Hypertens 2009; 27: $712-720$.

124 Shibuya Y, Ikeda T, Gomi T. Morning rise of blood pressure assessed by home blood pressure monitoring is associated with left ventricular hypertrophy in hypertensive patients receiving long-term antihypertensive medication. Hypertens Res 2007; 30: 903-911.

125 Nishinaga M, Takata J, Okumiya K, Matsubayashi K, Ozawa T, Doi Y. High morning home blood pressure is associated with a loss of functional independence in the community-dwelling elderly aged 75 years or older. Hypertens Res 2005; 28 : 657-663.

126 Shibamiya T, Obara T, Ohkubo T, Shinki T, Ishikura K, Yoshida M, Satoh M, Hashimoto T, Hara A, Metoki H, Inoue R, Asayama K, Kikuya M, Imai Y. Electrocardiographic abnormalities and home blood pressure in treated elderly hypertensive patients: Japan home versus office blood pressure measurement evaluation in the elderly (J-HOMEElderly) study. Hypertens Res 2010; 33: 670-677.

127 Asayama K, Ohkubo T, Hara A, Hirose T, Yasui D, Obara T, Metoki H, Inoue R, Kikuya M, Totsune K, Hoshi $H$, Satoh $H$, Imai $Y$. Repeated evening home blood pressure measurement improves prognostic significance for stroke: a 12-year follow-up of the Ohasama study. Blood Press Monit 2009; 14: 93-98.

128 Stergiou GS, Nasothimiou EG, Kalogeropoulos PG, Pantazis N, Baibas NM. The optimal home blood pressure monitoring schedule based on the Didima outcome study. J Hum Hypertens 2010; 24: 158-164.

129 Niiranen TJ, Jula AM, Kantola IM, Reunanen A. Comparison of agreement between clinic and home-measured blood pressure in the finnish population: the Finn-HOME Study. J Hypertens 2006; 24: 1549-1555.

130 Hosohata K, Kikuya M, Ohkubo T, Metoki H, Asayama K, Inoue R, Obara T, Hashimoto J, Totsune K, Hoshi H, Satoh H, Imai Y. Reproducibility of nocturnal blood pressure assessed by self-measurement of blood pressure at home. Hypertens Res 2007; 30: 707-712.

131 Kario K, Hoshide S, Shimizu M, Yano Y, Eguchi K, Ishikawa J, Ishikawa S, Shimada K. Effect of dosing time of angiotensin ii receptor blockade titrated by self-measured blood pressure recordings on cardiorenal protection in hypertensives: the Japan Morning Surge-Target Organ Protection (J-TOP) study. J Hypertens 2010; 28: 1574-1583.

132 Stergiou GS, Tzamouranis D, Nasothimiou EG, Karpettas N, Protogerou A. Are there really differences between home and daytime ambulatory blood pressure? Comparison using a novel dual-mode ambulatory and home monitor. J Hum Hypertens 2010; 24: 207-212.

133 Nakano H, Kikuya M, Hara A, Nakashita M, Hirose T, Obara T, Metoki H, Inoue R, Asayama K, Ohkubo T, Totsune K, Imai Y. Self-monitoring of ambulatory blood pressure by the microlife watchbp 03-an application test. Clin Exp Hypertens 2011; 33: 34-40.

134 Verdecchia P, Porcellati C, Schillaci G, Borgioni C, Ciucci A, Battistelli M, Guerrieri M, Gatteschi C, Zampi I, Santucci A. Ambulatory blood pressure. An independent predictor of prognosis in essential hypertension. Hypertension 1994; 24: 793-801.

135 Shimada K, Kawamoto A, Matsubayashi K, Ozawa T. Silent cerebrovascular disease in the elderly. Correlation with ambulatory pressure. Hypertension 1990; 16: 692-699.

136 Verdecchia P, Schillaci G, Guerrieri M, Gatteschi C, Benemio G, Boldrini F, Porcellati C. Circadian blood pressure changes and left ventricular hypertrophy in essential hypertension. Circulation 1990; 81: 528-536.

137 Ohkubo T, Hozawa A, Yamaguchi J, Kikuya M, Ohmori K, Michimata M, Matsubara M, Hashimoto J, Hoshi H, Araki T, Tsuji I, Satoh H, Hisamichi S, Imai Y. Prognostic significance of the nocturnal decline in blood pressure in individuals with and without high 24-h blood pressure: the ohasama study. J Hypertens 2002; 20: 2183-2189.

138 Bianchi S, Bigazzi R, Baldari G, Sgherri G, Campese VM. Diurnal variations of blood pressure and microalbuminuria in essential hypertension. Am J Hypertens 1994; 7: 23-29. 
139 Staessen JA, Thijs L, Fagard R, O'Brien ET, Clement D, de Leeuw PW, Mancia G, Nachev C, Palatini P, Parati G, Tuomilehto J, Webster J. Predicting cardiovascular risk using conventional vs ambulatory blood pressure in older patients with systolic hypertension. Systolic hypertension in europe trial investigators. JAMA 1999; 282: 539-546.

140 Boggia J, Li Y, Thijs L, Hansen TW, Kikuya M, Bjorklund-Bodegard K, Richart T, Ohkubo T, Kuznetsova T, Torp-Pedersen C, Lind L, Ibsen H, Imai Y, Wang J, Sandoya E, O'Brien E, Staessen JA. . Prognostic accuracy of day versus night ambulatory blood pressure: a cohort study. Lancet 2007; 370: 1219-1229.

141 Working Party of the International Diabetes Federation (European Region). Hypertension in people with type 2 diabetes: knowledge-based diabetes-specific guidelines. Diabet Med 2003; 20: 972-987.

142 Obara T, Ohkubo T, Kikuya M, Asayama K, Metoki H, Inoue R, Oikawa T, Murai K, Komai R, Horikawa T, Hashimoto J, Totsune K, Imai Y. The current status of home and office blood pressure control among hypertensive patients with diabetes mellitus: the Japan Home Versus Office Blood Pressure Measurement Evaluation (J-HOME) study. Diabetes Res Clin Pract 2006; 73: 276-283.

143 Ushigome E, Fukui M, Sakabe K, Tanaka M, Inada S, Omoto A, Tanaka T, Fukuda W, Atsuta H, Ohnishi M, Mogami S, Kitagawa Y, Oda Y, Yamazaki M, Hasegawa G, Nakamura N. Uncontrolled home blood pressure in the morning is associated with nephropathy in Japanese type 2 diabetes. Heart Vessels 2011; 26: 609-615.

144 Shea S, Weinstock RS, Starren J, Teresi J, Palmas W, Field L, Morin P, Goland R, Izquierdo RE, Wolff LT, Ashraf M, Hilliman C, Silver S, Meyer S, Holmes D, Petkova E, Capps L, Lantigua RA. A randomized trial comparing telemedicine case management with usual care in older, ethnically diverse, medically underserved patients with diabetes mellitus. J Am Med Inform Assoc 2006; 13: 40-51.

145 Pickering TG. Reflections in hypertension. How should blood pressure be measured during pregnancy? J Clin Hypertens (Greenwich) 2005; 7: 46-49.

146 Denolle T, Weber JL, Calvez C, Getin Y, Daniel JC, Lurton O, Cheve MT, Marechaud M, Bessec P, Carbonne B, Razafintsalama T. Diagnosis of white coat hypertension in pregnant women with teletransmitted home blood pressure. Hypertens Pregnancy 2008; 27: 305-313.

147 Rey E, Morin F, Boudreault J, Pilon F, Vincent D, Ouellet D. Blood pressure assessments in different subtypes of hypertensive pregnant women: office versus home patient- or nurse-measured blood pressure. Hypertens Pregnancy 2009; 28: 168-177.

148 Terawaki H, Metoki H, Nakayama M, Ohkubo T, Kikuya M, Asayama K, Inoue R, Hoshi $\mathrm{H}$, Ito S, Imai Y. Masked hypertension determined by self-measured blood pressure at home and chronic kidney disease in the Japanese general population: the Ohasama study. Hypertens Res 2008; 31: 2129-2135.

149 Agarwal R, Andersen MJ, Bishu K, Saha C. Home blood pressure monitoring improves the diagnosis of hypertension in hemodialysis patients. Kidney Int 2006; 69: 900-906.

150 da Silva GV, de Barros S, Abensur H, Ortega KC, Mion Jr D. Cochrane Renal Group Prospective Trial Register: CRG060800146. Home blood pressure monitoring in blood pressure control among haemodialysis patients: an open randomized clinical trial. Nephrol Dial Transplant 2009; 24: 3805-3811.

151 Agarwal R. Managing hypertension using home blood pressure monitoring among haemodialysis patients - a call to action. Nephrol Dial Transplant 2010; 25: 1766-1771.

152 Stergiou GS, Nasothimiou E, Giovas P, Kapoyiannis A, Vazeou A. Diagnosis of hypertension in children and adolescents based on home versus ambulatory blood pressure monitoring. J Hypertens 2008; 26: 1556-1562.

153 Furusawa EA, Filho UD, Koch VH. Home blood pressure monitoring in paediatric chronic hypertension. J Hum Hypertens 2009; 23: 464-469.

154 Krakoff LR. Cost-effectiveness of ambulatory blood pressure: a reanalysis. Hypertension 2006; 47: 29-34.

155 McGrath BP. Ambulatory blood pressure monitoring. Med J Aust 2002; 176 : 588-592.

156 Rickerby J. The role of home blood pressure measurement in managing hypertension: an evidence-based review. J Hum Hypertens 2002; 16: 469-472.

157 Funahashi J, Ohkubo T, Fukunaga H, Kikuya M, Takada N, Asayama K, Metoki H, Obara T, Inoue R, Hashimoto J, Totsune K, Kobayashi M, Imai Y. The economic impact of the introduction of home blood pressure measurement for the diagnosis and treatment of hypertension. Blood Press Monit 2006; 11: 257-267.

158 Fukunaga H, Ohkubo T, Kobayashi M, Tamaki Y, Kikuya M, Obara T, Nakagawa M, Hara A, Asayama K, Metoki H, Inoue R, Hashimoto J, Totsune K, Imai Y. Costeffectiveness of the introduction of home blood pressure measurement in patients with office hypertension. J Hypertens 2008; 26: 685-690.

159 Imai Y, Abe K, Sasaki S, Minami N, Munakata M, Sakuma H, Hashimoto J, Sekino H, Imai K, Yoshinaga K. Clinical evaluation of semiautomatic and automatic devices for home blood pressure measurement: comparison between cuff-oscillometric and microphone methods. J Hypertens 1989; 7: 983-990.

160 Kikuya M, Chonan K, Imai Y, Goto E, Ishii M. Accuracy and reliability of wrist-cuff devices for self-measurement of blood pressure. J Hypertens 2002; 20: 629-638.

161 Altunkan S, Oztas K, Altunkan E. Validation of the Omron 637IT wrist blood pressure measuring device with a position sensor according to the International Protocol in adults and obese adults. Blood Press Monit 2006; 11: 79-85.

162 American National Standard. Electronic or Automated Sphygmomanometers. Association for the Advancement of Medical Instrumentation: Arlington, VA, 1993.

163 American National Standard. Manual, Electronic, or Automated Sphygmomanometers. ANSI/AAMI 10: 2002. Association for the Advancement of Medical Instrumentation: Arlington, VA, 2003.
164 Prisant LM, Alpert BS, Robbins CB, Berson AS, Hayes M, Cohen ML, Sheps SG. American National Standard for nonautomated sphygmomanometers. Summary report. Am J Hypertens 1995; 8: 210-213.

165 O'Brien E, Pickering T, Asmar R, Myers M, Parati G, Staessen J, Mengden T, Imai Y, Waeber B, Palatini P, Gerin W. Working Group on Blood Pressure Monitoring of the European Society of Hypertension International Protocol for validation of blood pressure measuring devices in adults. Blood Press Monit 2002; 7: 3-17.

166 Health Policy Bureau, Ministry of Health, Labour and Welfare, Japan. Overview of Annual Reports on Statistics of Production by Pharmaceutical Industry. 2008 (in Japanese).

167 O'Brien E, Petrie J, Littler W, de Swiet M, Padfield PL, O'Malley K, Jamieson M, Altman D, Bland M, Atkins N. The British Hypertension Society protocol for the evaluation of automated and semi-automated blood pressure measuring devices with special reference to ambulatory systems. J Hypertens 1990; 8: 607-619.

168 Pickering TG. Clinicians's Manual on Self-Mmonitoring of Blood Pressure. London: Science Press, 1997.

169 Pickering T. . Recommendations for the use of home (self) and ambulatory blood pressure monitoring. American society of hypertension ad hoc panel. Am J Hypertens 1996; 9: 1-11.

170 Stergiou GS, Nasothimiou EG, Roussias LG. Morning hypertension assessed by home or ambulatory monitoring: Different aspects of the same phenomenon? J Hypertens 2010; 28: 1846-1853.

171 Miyakawa M. The influence of urination on home blood pressure measurements. Jpn J Med 2000; 89 (Suppl 1): 238.

172 Fujiwara T, Nishimura T, Ohkuko T, Imai Y. Rationale and design of HOME-BP study: Hypertension objective treatment based on measurement by electrical devices of blood pressure study. Blood Press Monit 2002; 7: 77-82.

173 Harada K, Karube Y, Saruhara H, Takeda K, Kuwajima I. Workplace hypertension is associated with obesity and family history of hypertension. Hypertens Res 2006; 29: 969-976.

174 Imai Y, Nagai K, Sakuma M, Sakuma H, Nakatsuka H, Satoh H, Minami N, Munakata M, Hashimoto J, Yamagishi T, Watanabe N, Yabe T, Nishiyama A, Abe K. Ambulatory blood pressure of adults in Ohasama, Japan. Hypertension 1993; 22: 900-912.

175 O'Brien E, Asmar R, Beilin L, Imai Y, Mallion JM, Mancia G, Mengden T, Myers M, Padfield P, Palatini P, Parati G, Pickering T, Redon J, Staessen J, Stergiou G, Verdecchia P. European Society of Hypertension recommendations for conventional, ambulatory and home blood pressure measurement. J Hypertens 2003; 21: 821-848.

176 Williams B, Poulter NR, Brown MJ, Davis M, Mclnnes GT, Potter JF, Sever PS, Mc GTS. Guidelines for management of hypertension: Report of the fourth working party of the British Hypertension Society, 2004-BHS IV. J Hum Hypertens 2004; 18: 139-185.

177 Stergiou GS, Skeva II, Zourbaki AS, Mountokalakis TD. Self-monitoring of blood pressure at home: How many measurements are needed? J Hypertens 1998; 16: 725-731.

178 de Gaudemaris R, Chau NP, Mallion JM. Home blood pressure: variability, comparison with office readings and proposal for reference values. J Hypertens 1994; 12: 831-838

179 Kawabe H, Saito I, Saruta T. Influence of repeated measurement on one occasion, on successive days, and on workdays on home blood pressure values. Clin Exp Hypertens 2005; 27: 215-222.

180 Kawabe H, Saito I. Which measurement of home blood pressure should be used for clinical evaluation when multiple measurements are made? J Hypertens 2007; 25: 1369-1374.

181 Kawabe H, Saito I. Correlation of repeated measurements of home blood pressure on one occasion and diagnosis of hypertension: study by measurement over seven consecutive days. Clin Exp Hypertens 2008; 30: 79-85.

182 van der Hoeven NV, van den Born BJ, Cammenga M, van Montfrans GA. Poor adherence to home blood pressure measurement schedule. J Hypertens 2009; 27: 275-279.

183 Mengden T, Hernandez Medina RM, Beltran B, Alvarez E, Kraft K, Vetter H. Reliability of reporting self-measured blood pressure values by hypertensive patients. Am J Hypertens 1998; 11: 1413-1417.

184 Imai Y, Obara T, Ohkubo T. How many times should we ask subjects to measure blood pressure at home on each occasion? J Hypertens 2007; 25: 1987-1991.

185 Mancia G, Sega R, Bravi C, De Vito G, Valagussa F, Cesana G, Zanchetti A. Ambulatory blood pressure normality: results from the PAMELA study. J Hypertens 1995; 13: 1377-1390.

186 Mancia G, Parati G. Clinical significance of "white coat" hypertension. Hypertension 1990; 16: 624-626.

187 Imai Y, Satoh H, Nagai K, Sakuma M, Sakuma H, Minami N, Munakata M, Hashimoto J, Yamagishi T, Watanabe N, Yabe T, Nishiyama A, Nakatsuka H, Koyama H, Abe K. Characteristics of a community-based distribution of home blood pressure in Ohasama in Northern Japan. J Hypertens 1993; 11: 1441-1449.

188 Tsuji I, Imai Y, Nagai K, Ohkubo T, Watanabe N, Minami N, Itoh O, Bando T, Sakuma M, Fukao A, Satoh H, Hisamichi S, Abe K. Proposal of reference values for home blood pressure measurement: prognostic criteria based on a prospective observation of the general population in Ohasama, Japan. Am J Hypertens 1997; 10: 409-418.

189 Imai Y, Ohkubo T, Sakuma M, Tsuji II, Satoh H, Nagai K, Hisamichi S, Abe K. Predictive power of screening blood pressure, ambulatory blood pressure and blood pressure measured at home for overall and cardiovascular mortality: a prospective observation in a cohort from Ohasama, Northern Japan. Blood Press Monit 1996; 1: 251-254. 
190 Obara T, Ohkubo T, Kikuya M, Fukunaga H, Murai K, Asayama K, Metoki H, Hashimoto $\mathrm{J}$, Totsune K, Imai Y. The present situation of home blood pressure measurements in Japan. J Blood Press 2006; 13: 447-454 (in Japanese).

191 Mazze RS, Simonson GD, Robinson RL, Kendall DM, Idrogo MA, Adlis SA, Boyce KS Dunne CJ, Anderson RL, Bergenstal RM. Characterizing blood pressure control in individuals with Type 2 diabetes: the relationship between clinic and self-monitored blood pressure. Diabet Med 2003; 20: 752-757.

192 Staessen JA, Thijs L, Ohkubo T, Kikuya M, Richart T, Boggia J, Adiyaman A, Dechering DG, Kuznetsova T, Thien T, de Leeuw P, Imai Y, O'Brien E, Parati G. Thirty years of research on diagnostic and therapeutic thresholds for the self-measured blood pressure at home. Blood Press Monit 2008; 13: 352-365.

193 Mancia G, Laurent S, Agabiti-Rosei E, Ambrosioni E, Burnier M, Caulfield MJ, Cifkova R, Clement D, Coca A, Dominiczak A, Erdine S, Fagard R, Farsang C Grassi G, Haller H, Heagerty A, Kjeldsen SE, Kiowski W, Mallion JM, Manolis A,
Narkiewicz K, Nilsson P, Olsen MH, Rahn KH, Redon J, Rodicio J, Ruilope L, Schmieder RE, Struijker-Boudier HA, van Zwieten PA, Viigimaa M, Zanchetti A. Reappraisal of European guidelines on hypertension management: a European Society of Hypertension Task Force document. J Hypertens 2009; 27: 2121-2158.

194 Thijs L, Staessen JA, Celis H, Fagard R, De Cort P, de Gaudemaris R, Enstrom I, Imai Y, Julius S, Menard J, Mion D, Palatini P, Rosenfeld J, Shapiro D, Spence D, Stergiou $G$. The international database of self-recorded blood pressures in normotensive and untreated hypertensive subjects. Blood Press Monit 1999; 4: 77-86.

195 Staessen JA, Celis H, Hond ED, Giot C, Leeman M, O'Brien E, Vandenhoven G, Fagard R. THOP investigators. Comparison of conventional and automated blood pressure measurements: interim analysis of the THOP trial. Treatment of Hypertension According to Home or Office Blood Pressure. Blood Press Monit 2002; 7: 61-62. 